Portland State University

PDXScholar

$1-1-2011$

\title{
Toward a Richer Shade of Blue: The Impact on Oregon Police Officer Perceptions of Racial Minorities After Anti-Racial Profiling Training
}

David Andrew Kline

Portland State University

Follow this and additional works at: https://pdxscholar.library.pdx.edu/open_access_etds Let us know how access to this document benefits you.

Recommended Citation

Kline, David Andrew, "Toward a Richer Shade of Blue: The Impact on Oregon Police Officer Perceptions of Racial Minorities After Anti-Racial Profiling Training" (2011). Dissertations and Theses. Paper 228.

https://doi.org/10.15760/etd.228

This Thesis is brought to you for free and open access. It has been accepted for inclusion in Dissertations and Theses by an authorized administrator of PDXScholar. Please contact us if we can make this document more accessible: pdxscholar@pdx.edu. 
Toward a Richer Shade of Blue:

The Impact on Oregon Police Officer Perceptions of Racial Minorities after Anti-Racial Profiling Training

by

David Andrew Kline

A thesis submitted in partial fulfillment of the requirements for the degree of

\author{
Master of Science \\ in \\ Sociology
}

Thesis Committee:

Melissa Thompson, Chair

Randy Blazak

José Padin

Portland State University

(C)2012 


\section{ABSTRACT}

Four fatal shootings, during police interactions, of unarmed people-of-color occurred in the Portland, Oregon Metro Area from 2003 to 2010 calling into question from members of the community whether or not the officers involved and hence their representative police departments had been racially profiling. Of interest in this study is whether or not cutting edge anti-racial profiling police officer trainings have an impact on how officers in Oregon perceive members of racial minority groups. A review of literature found that previous inquiries into racial prejudice among police officers may be present and that previous efforts to address racial ethics in law enforcement have had mixed results on officer perceptions of race. Using Whiteness Theory an examination was undertaken in Oregon utilizing a mixed methodological approach to answer three questions; 1) Do police officers report their perceptions of people-of-color being impacted as a result of participating in a racial profiling training seminar?, 2) Do police officers from the state of Oregon express having held a perception of members of the racial / ethnic community as individuals prior to attending a racial profiling training?, and 3) Do police officers from the state of Oregon report having held a stereotyped perception of racial / ethnic community members before attending a racial profiling training? Findings include that some officers may be racially prejudiced and others not, but that the training, according to those participating was not impactful upon their personal perceptions of people-of-color for reasons that they saw none or little personal bias within themselves although the seminar they attended brought police - race issues back into their conscious awareness. Despite the training being well-received by all the participants they suggested the training title and description may have dissuaded other officers from attending who may have benefited from its content and 
format. Transferability of the data's findings is weak due to a small sample size and other limitations of the study discussed. Nevertheless, conclusions about the effectiveness of the racial-profiling-training-under-review's ability to impact these officers' perceptions and attitudes of people-of-color are made and recommendations for police and social policy as well as suggestions for future research are discussed. 
TABLE OF CONTENTS

Abstract

List of Tables

List of Figures

CHAPTER ONE - INTRODUCTION

Purpose

CHAPTER TWO - LITERATURE REVIEW 11

Finding Consensus of Definition 11

Does Racial Profiling Exist? 12

$\begin{array}{ll}\text { Outcomes from Prior Racial Profiling Trainings } & 14\end{array}$

CHAPTER THREE - THEORETICAL FOUNDATIONS 19

Whiteness Theory 19

CHAPTER FOUR - METHODOLOGY 25

Research Design 26

Procedure $\quad 32$

Instruments 34

Quantitative Methodology Rationale $\quad 37$

Qualitative Methodology Rationale $\quad 37$

$\begin{array}{ll}\text { Data Analysis } & 38\end{array}$

Researcher Bias $\quad 40$

CHAPTER FIVE - FINDINGS 43

Research Question 2 44

Research Question $3 \quad 48$

Research Question $1 \quad 51$

CHAPTER SIX - DISCUSSION

Themes 66

Whiteness Within Law Enforcement 66

Avoidance of the Training $\quad 70$

$\begin{array}{ll}\text { Discussion } & 73\end{array}$

$\begin{array}{ll}\text { Conclusion } & 78\end{array}$

Limitations $\quad 82$

Suggestions for Future Research 86

Endnote $\quad 88$

References $\quad 92$

Appendix A - Initial Assessment Survey 99

Appendix B - Follow-up Interview Schedule 103

Appendix C - "It was over in seconds" 104 


\section{LIST OF TABLES}

Table 1 - Comparison of State and County Ethnic Demographics as Percentage of Estimated Total Population 


\section{LIST OF FIGURES}

Figure 1 - Frequency of Responses to Item 5 of Initial Assessment Survey

Figure 2 - Frequency of Responses to Item 6 of Initial Assessment Survey 


\section{CHAPTER ONE}

\section{INTRODUCTION}

"Training is a fundamental part of the police organization. It is a function of learning as well as teaching. Training not only prepares officers for the job, it also serves as a laboratory where we can think deeply about the meaning and essence of policing in a democratic society. By promoting open-minded and leading-edge thinking, the police

training contributes to the evolution of the police role in creating a free, diverse, and democratic society for all."

George Gascon

Commander, Training Group (LAPD)

June 2001

(Glenn et al. 2003:63)

One of the troubling problems permeating the U.S. justice system is racial disparities in arrest and incarceration rates. People with a conservative outlook tend to attribute the differences to higher offending rates among some races (Brown et al. 2003, Schafer et al. 2006). Indeed, the Federal Bureau of Investigation's Uniform Crime Reports (UCR) for 2009 shows, between the ages of 5 and 29, blacks, numerically, committed more homicides and bank crimes than whites (FBI 2010). However, Hawkins et al. (2000), Sampson and Wilson (2005) and Tonry (1995) note that because of weaknesses of both official reports (e.g. UCR) and victimization self reports (e.g. National Crime Victimization Survey) relying on them individually for offending rates is compromised. Therefore, accurate criminal offending is often jointly reliant upon multiple sources of arrest rates. Consequently, as an example of greater offending among blacks, conservatives may cite:

Arrests of white juveniles (under age 18) constituted 71 percent of all juvenile arrests compared with 26 percent for black youth. American Indian or Alaska Native and Asian or Pacific Islanders account for 1 and 2 percent, respectively. Black youth were overrepresented, given the fact that they make up 15 percent of the juvenile 
population compared with 79 percent white and 5 percent other races. (Hawkins et al. 2000:2)

Conservatives argue that these disparities in arrest rates verify disparities in offending rates and justify targeted policing of people-of-color to increase the efficiency of fighting crime (Schafer et al. 2006). Further rationalized by the political right, these tactics are justified as a cost-effective strategy toward fighting crime in light of limited resources available to many police departments (Kroes et al. 1974, Kroes 1985, Kop et al. 1999, Zhao et al. 2002, Schafer et al. 2006, Chapin et al. 2008).

Others with a comparatively liberal outlook contend institutional racism, and racial profiling, might explain the above evidence of disproportionality in arrest rates between races (Conley 1994, Wise 2008, McKinney 2000, Helfand 2005). To support their argument, liberals might site data from the National Crime Victimization Survey that illustrates in 2009 more blacks were victims of violent crimes than whites (Truman and Rand 2010) and note that according the UCR in 2009 among those 30 years old and greater whites numerically committed more homicides than blacks (FBI 2010). Moreover, early concepts of institutional racism were defined as a set of structural relations between whites and blacks of 1960s America, where one group (e.g. whites) had systematic advantage over the other (e.g. blacks) in terms of education, policing and labor (Scott and Marshall 2005). This "privilege of whiteness", often renders racism invisible among the white population (McKinney 2000). Through the functions of "white denial", racism has not yet been fully discussed and digested in American culture (McKinney 2000, Wise 2008).

Whiteness Studies, (a.k.a. White studies) offers an insightful perspective for addressing the critical intersection of race and policing. White studies scholars scrutinize the 
meaning of whiteness and draw attention to racial inequalities of the past and present within our society's institutions including education, housing and labor (Hirsh and Lyons 2010, Guitart and Gomez 2010, Hudson 2010, Menendez et al. 2010, Perlmutter 2008, Kurin 2008). They also tend to argue that white people still need to address and process the meaning of race, the vestigial racial inequalities stemming from the slave era and the consequences of current racial disparities (Friedman 2009).

Some past disproportionalities were brought to the cultural forefront during the mid1950s through the late-1960s, known as the Civil Rights Era of American history. Unquestionably, the Civil Rights Era was a period of great social unrest (Friedman 2009, Veterans of the Civil Rights Movement 2005). The incendiary relationship the police had during that time with racial minorities was one of the major points of contention in the struggle for racial equality (Veterans of the Civil Rights Movement 2005). The policing institution upholds our values of order but due to the legal system's mechanics, they can sometimes be the last agency within it to accommodate social changes (Armour 2008). Thus, the police could be characterized as a reactive institution. In terms of racial conflict, for example, recall the case of the "Little Rock Nine", where President Eisenhower intervened with the National Guard against the governor and state police of Arkansas, after nine black students were refused entrance to the formerly all-white Central High School, three years after the ruling in Brown v. Board of Education (1954) which outlawed segregation in schools (Veterans of the Civil Rights Movement 2005). Moreover, less than a year after the passing of the Civil Rights Act of 1964 on March 7, 1965, a group of 600 African-Americans attempted to march from Selma to Montgomery, Alabama in protest of resistance to African-American voter registration. They were stopped by a police blockade and beaten. 
Between 20 and 50 of the marchers were swept to the ground in the initial encounter and several others were beaten as all attempted to flee (Friedman 2009, Veterans of the Civil Rights Movement 2005). The incident was dubbed "Bloody Sunday" with the aid of media accounts and pictures of the event (Veterans of the Civil Rights Movement 2005).

Over the decades since the Civil Rights Era quieted and attained some of its goals, the nation's public has been witness to several cultural flashpoints involving police and people-of-color despite expanded access to institutions such as voting, education, labor, and housing. For example, the race riots between 1964 and the late-1970s in cities all over the country including New York City (1964); Detroit, Michigan (1967); Chicago, Illinois (1968); and Washington D.C. (1968) (Olzak, et al. 1996). Then, police-racial minority violence progressed into more modern history with the Miami Riot of 1980 spurred by the beating and death of a black motorcyclist fleeing police (Porter et al. 1984), and the Los Angeles, California Riots of 1992 spawned by the acquittal of four white police officers in a criminal case charged with severely beating a black motorist (Olzak, et al. 1996). And recently, evidence suggestive of police reactivity appeared in a mass march to city hall by 600 Portland, Oregon police officers and their supporters in reaction to a colleague under critical review for shooting a 12-year-old African-American female with a bean bag round on mass transit (Hannah-Jones 2010). When police actions are held up to scrutiny (Hannah-Jones 2010, Duin 2010), the police are often perceived to hold a united front and ignore public outrage. (Bernstein 2009, Blume 2002, Hannah-Jones 2010).

This unity as a group could be explained, partly, by the residual effects of general pressures related to law enforcement work as well as their identity as a member of "the Cops" formed through the bonds created during officer safety training (Holmes and Smith 
2008). Stressors that some officers may feel during their careers include the physical threats to their person (Scott 2004), as well as bureaucratic obstacles, limited support from supervisors, and insufficient resources (Kroes 1985, Kroes et al. 1974, Kop et al. 1999, Zhao et al. 2002, Chapin et al. 2008). Officer frustrations can also build around the demands of alternating periods of high and low work activity, having to work a second job to secure income, facing multiple expectations from outside sources, as well as possible conflicting values among co-workers (Kroes 1985, Kop et al. 1999, Chapin et al. 2008, Scott 2004). Furthermore, aggravations may arise from accommodating many judicial restraints and a negative public image of officers (Kroes 1985, Kroes et al. 1974, Scott 2004). If officers poorly manage their stress levels, their reactions to stress may become more pronounced and reflexive (Westman and Walters 1981, Lehrer et al. 2007) possibly putting their racial sensitivity in jeopardy (Altman 2000, Perry 2001, Armour 2008). As I will discuss in the next chapter, racism remains a marginally discussed topic within our society and is expressed in subtle ways that White Studies scholars work to address. Police officers, then, products of our society like all citizens (Walker et al. 2000), might be unaware of the racialized structure of our society without quality training (Armour 2008). Without excellent training, the police, risk inadvertently perpetuating racial hierarchies that remain in our cultural narrative (Armour 2008).

Training which confronts racial profiling, one of the tools used to address problematic biased behavior in law enforcement, once thought to be a viable avenue toward tension reduction in the community are, nonetheless, a source of controversy (Barlow and Barlow 1993). The objective of these trainings is to develop and identify ethical tactics and procedures when working in multicultural communities so they can more effectively fight 
crime (Barlow and Barlow 1993). Challenges to negative perceptions of racial minorities may be weakened in racial profiling training programs to avoid attendee resentments and counter-productive defense mechanisms (Barlow and Barlow 1993 Kroes 1985, Kop et al. 1999). Because of these issues, racial profiling trainings have in the past been toned down and "sugarcoated" so that it is well received by officers (Barlow and Barlow, 1993).

Moreover, some police officers around the country report that racial profiling trainings have served as merely "window dressing" for their departments (Cashmore 2002). Therefore, racial profiling trainings cannot be an afterthought of the overall training regimen and must be effective in supporting officer ethics while empowering them to actively police the community.

Locally, police in the Portland, Oregon metro area have been under intense examination for the fatal shootings of unarmed people-of-color in the recent past (Bernstein 2004, Denison 2004, Terry 2010). Four cases can be noted among several: Kendra James (2002), James Jahar Perez (2004), Fouad Kaady (2005) and Aaron Campbell (2010). Each died in separate altercations with police. From media accounts, the perception of people-ofcolor is that the police have failed to take their interests seriously, and that the cases are evidence of racism within the police force, rather than simply the actions of rogue officers (Hannah-Jones 2010, Duin 2010). From this minority perspective, the circumstances leading to each of these events, and their subsequent investigations, appear suspicious and involve questionable policies and practices, which may condone or tolerate extra-legal behaviors of officers based on perception of race (Hannah-Jones 2010). Media coverage suggests the racial minority community faults police administrators with denying the possibility of racism and racial profiling within the police institution (Hannah-Jones 2010). To a skeptical 
outsider, this denial might appear to reflect institutional racism. However it is not conclusive whether the actions of the officers involved in the four cases above rise to the level of "racism". In fact, when confronting racism and racial profiling in law enforcement, discussions between some members of the public and members of the police are centered on differing perceptions of racism.

To illustrate this problem of racism's and racial profiling's subjectiveness, take the case of James Jahar Perez, who was a young, unarmed African American male, as an example. As presented in The Oregonian (Bernstein 2004) newspaper (see Appendix C for full article):

Twenty-four seconds elapsed between the time that [a Portland officer] radioed the traffic stop of James Jahar Perez on Sunday and [an officer's] radio call that shots were fired...

The first radio call may have come as [the officer] already had stepped from his car and was approaching Perez in the parking lot of a drycleaner.

[The officer who fired], pulled over Perez at 5:07 p.m. Sunday at North Fessenden Street and North Burr Avenue for failure to signal within 100 feet of making a turn. In less than 30 seconds, [the officer] had fired three shots from his $9 \mathrm{~mm}$ at Perez because he thought the motorist was armed, police said.

Perez, 28, died from a wound to the chest.

The Oregonian presents the Perez case as a possible racial profiling incident based on witness accounts at the scene and community leader's reactions to the news of his death (Bernstein 2004, Denison 2004). "Could members of the police be racially prejudiced?" and, "Does anti-racial profiling training for police officers in the state of Oregon confront racial prejudice?" are questions arising from this case and the other three which have spurred the present inquiry. I do not answer specific questions regarding the presence of racial profiling 
in each of the above noted cases. Mr. Perez, for example, may have been known personally by the officers involved and if they did, the officers may have known whether or not he had a violent background explaining much about their approach to his vehicle and their reaction to him. From a sociological stand point the details are not of interest. Rather how the police, as a specific group of people see themselves in relation to the multicultural society America has developed into, is what is of interest to me in this research (Hannah-Jones 2010, Terry 2010). Questions I draw from examples such as the above fatal altercations revolve around perspectives officers hold prior to interacting with people-of-color they address and process and if their perspectives are prejudicial, how well does the training they undergo impact those perspectives.

\section{Purpose}

The difficulty of proving racial profiling allegations is very difficult because we live within a postmodern paradigm were anyone's perception may have equal validity as someone else's. Proving racial profiling happened in the above cases is not the purpose of this project. Rather, the suspicion of racial profiling is a crisis of legitimacy for a police department in the postmodern era (Withrow 2007, Armour 2008, Dunham and Wilson 2008, Weitzer and Tuch 2005). It should be treated as a real problem for the police department in which allegations of racial profiling are made, despite skepticism surrounding it within law enforcement and conservative circles (Dunham and Wilson 2008, Brown et al. 2003).

Departments, whose policies and practices follow the conclusions of racial theorists with a conservative slant (Brown et al. 2003), risk distancing themselves from racial minority communities and fortifying subjective racial hierarchies if their training fails to confront 
racial prejudice.

Missing in the body of previous research is a direct examination of training procedures in the state of Oregon to gauge whether they confront the difficult intersections of police, race and bias. In the wake of repeated racially-sensitive fatal altercations with people-of-color in Oregon, as recently as 2010 (Hannah-Jones 2010, Duin 2010), such an examination is overdue and timely to reassure skeptical members of the public that the police continue working toward an equitable multiculturalism. The purpose of the present research is to assess if officer perceptions of people-of-color are impacted by a currently practiced anti-racial profiling training model in the state of Oregon. Previous research does not appear to have examined anti-racial profiling training in this broad geographical region prior to this study.

The next few chapters attempt to answer the following question, through the exploration of previous research, theory, and first-hand data collection. This central question gathers data related to the effectiveness of anti-racial profiling trainings' impact on officer perceptions of people-of-color. In practice:

1. Do police officers report their perceptions of people-of-color being impacted as a result of participating in an anti-racial profiling training seminar?

However, in order to measure the impact of the training on officer perceptions I must first ask whether or not the officers report a perception of people-of-color as a twodimensional cultural stereotype or as a full person of individual characteristics. Therefore, this inquiry is addressed as 2 separate peripheral questions to establish reference points to 
the above central question of research:

2. Do police officers from the state of Oregon report having held a stereotyped perception of racial / ethnic community members before attending an anti-racial profiling training?

3. Do police officers from the state of Oregon express having held a perception of members of the racial / ethnic community as individuals prior to attending an antiracial profiling training?

Prior research has attempted to concretely identify the existence and effects of racial profiling with mixed results (Conley 1994, Schafer et al. 2006). Some of these studies will be presented in the next chapter to further illustrate the differing conclusions of either side of the racial profiling debate. The remainder of this work will focus on answering the above questions and discussing their implications. Chapter 2 is a review of literature to assess other scholars' conclusions regarding racial profiling, Chapter 3 outlines theoretical perspectives that may help answer questions born from harmful interactions between police and the racial and ethnic minority communities they serve. Chapter 4 will discuss the methodological approach of this research. Chapter 5 will present the findings of this project and Chapter 6 will address the findings' impact on the theories used to explain the impact of racial profiling and make conclusions for the advancement of police and social policy. 


\section{CHAPTER TWO}

\section{LITERATURE REVIEW}

This chapter will explore some of the prior research which has sought to identify racial profiling as a legitimate problem. First, I will define racial profiling and address the existence of it based on the two major political perspectives. Then, I will present past research to bring understanding of how prejudiced policing may manifest itself in law enforcement. Finally, the chapter discusses research that has provided insight into previous anti-racial profiling training's ability to impact police officer attitudes and preconceptions of people-of-color. Training that encourages officers to critically address racial prejudice is an important but often underappreciated topic in law enforcement (Barlow and Barlow 1993, Marion 1998).

\section{Finding Consensus of a Definition:}

One of the key elements of controversy over racial profiling can be attributed to a lack of a consistent definition. Law enforcement communities, academic circles and the public have not come to agreement. The competing perspectives on racial profiling leave one with a largely binary choice to make; either it is the result of good police practices and a coincidence, based on co-occurring factors, or it is an abstraction that feels unjust to those criminally targeted. One's choice in this matter likely is a result of how they define racial profiling. Finding a consistent definition can be difficult even after nearly 20 years of study.

A commonly held public and media definition of the problem is in broad terms; "racial profiling" describes a situation where race is any one of the factors motivating an 
officer to stop, search, or arrest a person-of-color (Miller 2007). To underscore this, racial profiling, in one definition, happens when an officer incorporates race as "one of the factors in any profile that affects police discretionary action" (Dunham and Wilson 2008:248). Furthermore, Novak offers a similar definition of racial profiling; "an instance when police use race as a key factor in deciding whether to initiate a traffic stop" (Novak 2004:67).

In contrast, many law enforcement agencies define racial profiling with more specificity, referring to a situation when a decision is made where race is the only factor explaining discretionary action (Simon Weisenthal Center Museum 2002). This definition brings racial profiling behavior into a very particular and yet more descriptive set of actions. If the previous definition were used to define racial profiling, every interaction or search for a suspect of color would be considered racial profiling. Because of its specificity, the law enforcement definition has been adopted as the measure of reference in this study because it enables greater meaningful analysis through its precision of scope.

\section{Does Racial Profiling Exist?}

There is a vast body of research which makes clear many scholars and authors have addressed the problem of racial profiling in the United States (Miller 2007, Schafer et al. 2006, Kavanagh 1997, Conley 1994, Liederbach et al. 2007, Dunham and Wilson 2008, Withrow 2007, Kirchbaum et al. 2001) and internationally in Canada (Das 1993), Australia (Avery 1989; Prenzler and Ronken 2003), Finland (Pitkanen and Kouki 2002), England (Garland and Chakraborti 2007; Loftus 2008; Rowe and Garland 2003; White 2006; Young 1993), Taiwan (Sun and Chu 2008), and Germany (Terkessidis 2000). Focusing on research conducted with the American police force, there are generally two competing perspectives in 
the discourse on racial profiling: conservative and liberal (Brown et al. 2003).

There is a special term, though, for those people who follow a mostly conservative approach to race relations, the racial realist (Brown et al. 2003). Racial realists believe their stance is grounded in hard realities, which, they claim, liberal versions of race relations ignore or minimize (Brown et al. 2003). In terms of law enforcement, the argument of racial realists is that racial profiling does not exist because the police respond to crime and calls for crime control (Brown et al. 2003). Therefore, disparities in targeting, arrest rates, and further sanctions are justified based on rates of criminal offense between the races (Brown et al. 2003, Hawkins et al. 2000, Sampson and Wilson 2005, Tonry 1995).

In comparison to the racial realist position, other researchers focus on the perspectives of those affected by the criminal justice system and explore outcome disparities between whites and people-of-color (Conley 1994, Brown et al. 2003). Much like the "dark figure of crime", where much crime eludes detection because it never goes reported, Conley (1994) and others (Hannah-Jones 2010) reveal how racial profiling may occur and yet evades statistical detection because police interactions with the public are not always documented. Conley (1994) points out that research not taking into account the initial interactions peopleof-color have with some law enforcement personnel neglect the complete understanding of the relationship between police and racial minorities (Hannah-Jones 2010). Repetitive negative interactions bolster allegations of racial profiling, which intensifies and prolongs the strength of those allegations (Conley 1994, Holmes and Smith 2008).

Being one of the most stressful jobs, the demands of police work may wear on the average officer to the point that some actions and behavior that appear to resemble racial profiling are simply a function of a lack of affective coping strategies. Again, the physical 
threat to their being (Scott 2004), poor job supports, negotiating a mammoth bureaucracy (Kroes 1985, Kroes et al. 1974, Kop et al. 1999, Zhao et al. 2002, Chapin et al. 2008), managing a large work load, as well as aggravation with legal restraints, might all contribute to highly charged reactions by law officers regardless of the suspect's race. These job stressors may contribute to reactions to suspects that appear unnecessary to outside observers in racially charged interactions (Westman and Walters 1981, Lehrer et al. 2007).

To summarize these perspectives, despite research that minimizes the effect of race on officer discretionary actions and attempts to explain police - race relations as "colorblind", other research, suggest there are methods, undetected interactions and severe job pressures that might allow racial profiling to happen.

\section{Outcomes from Prior Anti-Racial Profiling Trainings}

Previous research assessing anti-racial profiling trainings appears limited. Some studies have examined officer outcomes in regards to the training impacting their perspectives of racial and ethnic minorities.

First, establishing a level system for evaluating anti-racial profiling trainings, Glenn et al. (2003) discuss as a case study the Los Angeles, California Police Department's evaluation of their racial profiling training regimen using the Continuing Education Delivery Plan (CEDP), an education model for adult learning incorporating student interaction and discussion. The CEDP sets up levels of evaluative rigor in four steps: Reaction, Learning, Behavior, and, finally, Results (Glenn et al. 2003). Glenn et al. (2003) describe these levels in the following synopsis: Reaction is the initial response to training, typically found in end-oftraining satisfaction surveys; Learning measures what was absorbed from the training; 
Behavior refers to what individual actions were changed, and, finally; Results measure tangible outcomes of the training in an organizational sense often measured by numbers of citizen complaints made and settlement amounts in lawsuits where the police have been judged at fault. In their review, Glenn et al. (2003) found the LAPD attained the second level of evaluation (i.e. Learning) because it surveyed their officers post-training and interviewed them at a later date to assess what insight they held onto from the training. The CEDP model provides a comprehensive scope for further study and evaluation efforts.

Building from the structure provided by Glenn et al. above, Kirchbaum et al.'s (2001) study of the exploration and revision of the Detroit Police Department's anti-racial profiling seminars. In 1999 the Detroit, Michigan Police Department held a conference in which racial profiling was accepted as a current unofficial and problematic practice within the department. Consequently, during the conference, in an attempt to combat racial profiling in the DPD, 6 key targets were identified that would improve the quality of anti-racial profiling trainings:

- Collaboration of the law enforcement agency (inclusive of all tiers of the command structure)

- Measurement, Evaluation and Outcomes (such as the LAPD study above)

- Community Involvement (feedback and presentation from racial groups)

- Guest Law Enforcement Presenters (trained police staff that relate to the officer attendees)

- Inclusion of the Principles of Adult Education (similar to the CEDP of the LAPD study)

- Involvement of the Command Structure (to provide authority and validity to the training)

(Kirchbaum et al. 2001, italicized text added for explanation)

In response to the creation of these 6 targets, a 4 day training course was later implemented at the academy level that addressed each target (Kirchbaum et al. 2001). After an initial run 
of the proposed course, the outcomes were found to be two-fold. Implementing, affectively, the two lower levels of evaluation from the Glenn et al. study above, pre- and post-training attitude and behavior assessments, from a subset of officers in attendance at the workshop, Kirchbaum et al. (2001) found 1) significant change in attitude and behavior in 70 percent of officers and 2) between 60 and 70 percent of officers interviewed reported specific examples of behavior and attitude changes, as well as examples of alternate conflict resolution learned in the workshop.

Similar in research design as Kirchbaum et al. (2000) above, Myrna Cornett-DeVito and Edward McGlone (2000), utilizing the Cross-Cultural Adaptability Inventory, conducted a pre-and post-test of several types of law enforcement cultural seminars, and measured officers' change of perception in regard to people-of-color. Their objective was to determine whether culture-specific types of seminars or cultural-general types of seminars resulted in the greatest positive outcomes. An example of a culture-specific format for such a seminar would consist of having a member of a cultural minority talk to officers about their specific cultural practices. Conversely, the culture-general type of seminar would consist of instructors presenting material that pertains to how officers interact ethically within the breadth of cultural minority communities they may serve. Cornett-DeVito and McGlone's results indicate significant positive outcomes occurred under the culture-general approach to training, with the caveat that the training is interactive and instructors are regarded as qualified.

Not all cultural sensitivity, ethics, anti-racial profiling trainings were found to have positive outcomes. Controversy over cultural competency, multicultural, or anti-racial profiling trainings has held steadfast in the debate over ethical training in law enforcement. 
Negative outcomes have been found in reviews of several prior studies. Of these, Marion (1998) and Barlow and Barlow (1993) discovered how officers reacted to these trainings and how they might be used by officers to cover their biases.

Using a different methodology, participant observation, Marion (1998) discovered a negative outcome from the ethics and cultural sensitivity block from the officers in her recruit training cohort. Marion (1998) went incognito to examine the police academy training experience. Unfortunately, in her assessment of how police recruits perceived the training during the cultural competency and ethics block, she found few examples of serious reflection and learning. Conducted on a local university campus, Marion's assessment was that the training was well intentioned by the instructors, but returned limited positive results from the cadets.

"The student response to the whole topic... was poor. Some did not take the training seriously and had more fun at what was being said than trying to learn from it. They used derogatory terms to describe cultures or genders (chink, bitch, dago) and made jokes about what was said. They didn't accept the fact that cultural diversity will have a big impact on their jobs and therefore is an important subject to discuss. They said that these attitudes do not exist, that they themselves do not have them, or that they would not treat suspects differently based on racial or ethnic characteristics. The few students who were serious about the class were intimidated and refused to take part." (Marion 1998:65)

Similarly, Barlow and Barlow (1993) conducted a study of racial and cultural awareness trainings among police officers and discovered that these trainings may become increasingly weak at addressing biases the officers may have had. They found this process of diluted prejudice-confrontation operated in the following way. Officers in their study who had participated in a cultural sensitivity training were likely to evaluate most positively trainings that were easily received and the least confrontational toward officers' racial 
prejudice. Then, the cultural trainings with the highest satisfaction rates were the training programs that were invited back for the next group of officers to undergo these type of trainings, which in effect filtered out the trainings that meaningfully addressed racial bias within police work. Furthermore, Barlow and Barlow found that some of these trainings that were highly praised by the officers were used by the officers to mask their biases. During one of these trainings, Barlow and Barlow quote an officer's question to the instructor, "How can I use this training so that I can pull over an African American and not be seen as doing it for racial reasons?"

So it appears cultural sensitivity type training programs that incorporate a clear structure of assessment, that acknowledge the existence, or the perception, of biased-based policing in a department, the development of a comprehensive training regimen that uses a cultural-general approach, lead by respected instructors have the greatest probability of positive officer outcomes. Conversely, the training programs Without such parameters, the trainings may be a devalued by officers.

This chapter has been an exploration of previous research, with the intention of explaining how police officers might engage in racial profiling behavior and what is perceived to be biased-based policing; operationalizing the internal thought processes and stressors accompanying police work, and, finally, exploring how racial profiling trainings are approached by officers and recruits and in what ways they affect those who partake in them. The next chapter presents theories which help explain how and why racial profiling can occur, sometimes without conscious intent. 


\section{CHAPTER THREE THEORECTICAL FOUNDATIONS}

Perceptions that racial profiling is practiced in policing, has been identified as a problem for the policing institution (Glenn et al. 2003). The review of literature has helped frame and give reference to this investigation. Now, our attention will be turned toward explanation of bias within a grander view that establish a lens in which to examine why racial profiling occurs, its processes and a theoretical frame to assess how anti-racial profiling trainings succeed or fail at impacting problematic perceptions of people-of-color. In this effort Whiteness Theory may be an appropriate theoretical basis in which to look at this issue.

\section{Whiteness Theory}

Whiteness Theory holds white privilege and white denial as its paramount concepts of interest. It has sought to critically examine whiteness and identify what it means to be white in American culture. The tenets of white privilege are 1) it is normalized to the point that whiteness becomes the standard to reach for all people in the culture, 2) it is mostly invisible to whites because it is normalized and, 3) because it is invisible, whites are enabled to avoid directly addressing the structural racial inequalities within society, thereby perpetuating those inequities and the privilege itself (Brown et al. 2003).

White privilege is the result of social constructs created by the socially powerful to artificially elevate the status of whiteness and decrease, marginalize, and ignore the experiences of people-of-color (Helfand 2005, McKinney 2000). Because it is omnipresent, 
"everyday whiteness", the accumulation of mundane occurrences in life that serve to advance white people and oppress people-of-color, is normalized (McKinney 2000). Moreover, the vestiges of American historical race relations have ensured that, with little question, whiteness goes unchecked and remains invisible to those who possess it (Helfand 2005, McKinney 2000, Loewen 2007).

Whiteness scholars argue that race "works" for white people but it does not for people-of-color through the function of white privilege (Helfand 2005). Simply stated, the division of people, based on arbitrary racial perceptions, created by whites and maintained through the process of "doing race" perpetually recreates a race-value hierarchy where whites' opinions and concerns are always valued at a premium, over those of people-ofcolor. (Perry 2001, Altman 2000). Since race works for whites, they do not experience its burden in the same way as people-of-color, and are consequently less inclined to address it meaningfully, i.e. to think about its consequences and windfalls (Helfand 2005).

Theorists such as Helfand (2005) Wise (2008) and Roediger (1999) argue the class ceiling, the system of disadvantages, hardships, and obstacles for people-of-color to social mobility, has historically made it difficult to impossible for people-of -color, African Americans especially, to access the benefits of the upper classes. They argue these obstacles are still intact in the present day in subtle forms and even subconscious practices (Wise 2008). They identify the ways the dominant racial group, i.e. whites, think about their reality and obfuscate the unpleasant issue to enable their denial of privilege when they "do race" (West and Fenstermaker 2002). In support of this, some police officers use jargon to deflect and minimize broad patterns of thinking about different groups of people. Take, for example, Schafer et al. (2006) and the police's invocation of a "working personality" among 
law officers, a term synonymous with organizational culture (i.e. a set of collectively held beliefs and values). "Working personality" enables responding officers to work with the public in "perceptual shorthand", framing interactions for ease and routine (Schafer et al. 2006). Hence, the young Hispanic male in street clothes may be thought of as a potential gang member, shorthand which aids and instructs the officer to approach the person of interest with an "appropriate" frame of mind (Schafer et al. 2006). Yet, "working personality" and "perceptual shorthand" may be coded language for biased-based policing and an effort to deracialize interactions with people-of-color. Altman (2000) and Walker et al. (2000) would likely concur that all people socialized to American culture do the same as a result of being aware of the race value hierarchy. Care, through attentive training or life experience, must be taken to recognize when "working personality" and "perceptual shorthand" are being applied in a biased context (Armour 2008). This kind of avoidance and denial may perpetuate inequalities in a fashion that may be undetectable at first glance.

To address this, Armour (2008) discusses the consequences of white denial in a courtroom setting but her ideas appear applicable to police ethics and anti-racial profiling trainings. During a jury trial, expressly identifying a litigant's protected class is prohibited for concern that it would unduly influence members of the jury, essentially an attempt to avoid confronting the racial value order (Armour 2008). However, Armour argues that because bias is socialized into our culture and our ideology (Altman 2000, Perry 2001), without direct examination of the biases associated with the protected class, justice is never fully served. Just as members of the jury are instructed to ignore inherent biases between groups, police personnel, who ignore the existence of biases against members of a protected class (e.g. racial minorities), risk perpetuating unjust legal outcomes because they haven't been trained 
to identify the normalized racial hierarchy and its relation to their position of power.

Moreover, training which assists officers' understanding of how bias affects interactions between themselves and the community and how they can empower themselves to actively and ethically police is needed (Barlow and Barlow 1993).

Armour (2008) further explains that through reflexive acts the average person assigns labels to others based on limited information, and put them into different categories. When interpreting a stranger's status, or class, people fail to conduct an exhaustive search for the accurate social category (Armour 2008). Instead, what occurs is a retrieval of only the most accessible knowledge, usually a stereotype, and then forcing the new information to fit the stereotype, akin to "pounding a square peg into a round hole" (Armour 2008). This is much like Duncan's model of "priming" (Armour 2008). "Priming" names the process where a person is exposed to limited knowledge regarding a different person or group which evokes a strong emotional reaction. Later, the person associates those emotional definitions to random and meaningless interaction with members of the different group (Armour 2008). Conley (1994) would concur and attest that the undocumented interactions some police officers have had with people-of-color serve as a priming event and reinforce their working personality (Schafer et al. 2006).

Given that, on a grand scale, priming occurs repetitively over the course of one's life and builds into a foundation of reflexive thought, Armour (2008) suggests the dissociation model of automatic and controlled processes can be utilized to overcome deeply held biases. Dissociation modeling entails a conscious and active addressing of one's bias through selftalk and/or spending time with people critical of the bias in question (Armour 2008, Dunham and Wilson 2008). Furthermore, racial prejudice is such a deeply entrenched social 
bias, even non-prejudiced people behave and tacitly support racism without conscious motive (Armour 2008). "Non-prejudiced responses take intention, attention, and effort," to become more habitual (Armour 2008:24). Since all people raised or accustomed to American culture likely have some concept of the racial hierarchical system, and, since the police are not unlike most citizens, this anti-racism tactic could be applied to racial profiling training among police officers even those who report no racial prejudice (Altman 2000, Walker et al. 2000). Previous research suggests officers-of-color may also benefit from disassociation modeling training due to findings that their perceptions of racial minorities are surprisingly similar to those of white officers (Walker et al. 2000).

The training environment should be an opportune time for these deep-rooted social structures to be discussed and individually reflected upon by the officers in attendance. Police officers may be reluctant to disclose their perceptions of people-of-color because of past and even present tensions between them as well as concern for how their perceptions will be interpreted by outsiders who have greatly scrutinized their behaviors as well as to conform with social canons (Kroes 1985, Kroes et al. 1974, Scott 2004). The stressors felt in police work appear to be a starting point when discussing race, reflexive thoughts, stereotypes, power/control issues in relation to policing in a diverse society which may allow the officers to speak freely about their social ideologies and thoughts about social structure in a supportive context.

In closing, Whiteness Studies is utilized in this research to explain how the police have approached community relations in the past. The next chapter outlines how the literature review in Chapter 2 and the theories discussed in this chapter have been grounds 
for the examination of challenges to racial prejudice among Oregon police. 


\section{CHAPTER FOUR}

\section{METHODOLOGY}

"Evaluation provides a self-policing means of measuring instructor effectiveness and officer expertise.” (Glenn et al. 2003:66)

The previous chapters have identified the issues accompanying racial-profiling accusations against police departments in the state of Oregon, reviewed previous relevant research, and explored theoretical explanations which can be used to understand why it happens, and how it may be reduced or eradicated. This chapter describes how this project attempts to answer the research questions. It outlines this study's methodology following from the theoretical precepts set forth in the preceding chapter.

This chapter describes the process of the present research project; how the evaluation of a state-of-the-art police ethics and anti-racial profiling training seminar was completed. First the research design will be discussed, including descriptions of the research sites and participants, procedures and data collection instruments. Next the rationale for the methods used will be presented, followed by a discussion of the data analysis strategy. This chapter concludes with a discussion of areas of potential researcher bias, and the steps taken to address this issue.

The purpose of this thesis is to identify participating officers' self-reported, prior-tothe-training perceptions of racial minorities and then to explore the impact of the training experience on those perceptions. This study is essentially a follow-up to an exploratory study conducted by researchers in the Criminal Justice Department at Portland State University. For their study, a self-administrable, brief, both qualitative and quantitative survey was given to each officer in attendance on the day the racial profiling training was 
presented. In short, the current project incorporated data culled from the voluntary participants' surveys and collected their reports of how the training impacted their perceptions of people-of-color using individual qualitative telephonic interviews.

\section{Research Design}

This project is designed largely as a case study. In a case study, the focus of the research "is that of a single case or a few selected examples of a social entity," (Scott and Marshall 2005). The person or entity examined in case studies are often studied in greater depth than subjects in quantitative research designs because the nature of the research question(s) differs. Case studies are often beneficial to the research when answers of deep subject content is what is of interest and, with human subjects, a strong rapport with members of the sample is needed to attain them. There are a variety of approaches research may take in a case study and often several different data collection strategies are employed to strengthen the validity of the project (Scott and Marshall 2005). Case study data collection strategies include, but are not limited to; interviews, participant and non-participant observation, and content analysis (Scott and Marshall 2005). However there are no well defined structures for case-study research (Scott and Marshall 2005).

The case study method is used in this research for many of the above defined reasons; examination of a social entity, the need for depth of subject content, the ability to build rapport with the participants, and interviewing participants rather than surveying them. But in addition, the case study method requires an investigator to reach both the thresholds of conceptual validity and reliability to make the project sound (George and Bennett 2005). However, Robert Yin (2009) goes further and describes validity as three distinct parts; 
Construct, Internal and External. These thresholds are used as tests for a case study to be judged against. Yin notes that construct validity entails "identifying the correct operational measures for the concepts being studied." (Yin 2009:40) and is often achieved by using "multiple sources of evidence, establishing a chain of evidence, and having key informants review the draft," (Yin 2009:41). Internal validity is met when the investigator is "seeking to establish a causal relationship, whereby certain conditions are believed to lead to other conditions, as distinguished from spurious relationships," (Yin 2009:40). Pattern matching, explanation building, addressing rival explanations, and using logic models are four tactics used to fully satisfy a case study's attempt to meet internal validity (Yin 2009). External validity occurs when the investigator "defines the domain to which a study's findings can be generalized," (Yin 2009:40). Theory drives case study research toward it in single case studies, while replication logic increases external validity in multiple case studies (Yin 2009). The threshold of reliability is met when the investigator is able to "demonstrate that the operations of a study, such as the data collection procedures, can be repeated, with the same results," (Yin 2009:40) Clearly describing the case study protocol and the development of a case study database are helpful in this regard. Although, Yin (2009) states that few, if any, studies using the case study method have been able to achieve all of these measures to their fullest. That being said, the remainder of this chapter describes my efforts to meet these standards.

As descriptive models, Yin (2004) gathered several past studies for comparison. Of these, one that appears apropos to this study is "Implementation: How Great Expectations in Washington are Dashed in Oakland" by Pressman and Wildavsky (1973). In their project they sought to document "the challenge of putting a federally inspired program into place in 
a local community." (Yin 2004:48). In so doing the study is a examination of how locals react to "change" from a distant authority. The significance of Pressman and Wildavsky's work is that it was the first major study on the implications of attempts at social restructuring (Yin 2004). Taking a look at the effects and reactions to the first installment of federal aid in the creation of "The Great Society" the research has been considered a model for other case studies because "their case study showed both how to collect sound data on an abstract topic and how to simultaneously develop new conceptual insights." (Yin 2004:48). Pressman and Wildavsky's work serves as a model to this research in that their data collection strategy, interviews and content analysis, is well documented and their method of developing conceptual insights elicits inspiration.

Another model case study is that of Jeffrey M. Paige (1975), "Agrarian Revolution: Social Movements and Export Agriculture in the Underdeveloped World," picked by George and Bennett (2005) as an exemplary standard. A sociologist, Paige sought to describe "the effect of the agricultural export economy on social movements of cultivators in plantations and farms in the developing world." (George and Bennett 2005:298) and he used the cases of Peru, Angola and Vietnam to refine and trace the process of his theory explaining "how and why different modes of production in export agricultural societies generate different rural social movements." (George and Bennett 2005:298). Paige's research appears as a model because of his use of mixed methods, e.g. using a quantitative study as basis for his theory and congruently checking it with the 3 case studies to demonstrate and refine that theory. In this research, I use both quantitative an qualitative research strategies and the data that they produced to assist in the formulation of conclusions as to what may enable greater positive police officer perception impacts from anti-racial profiling trainings. 
The Research Sites:

For protection of the research participant's identity, the exact location, and specific names of departments and towns are being withheld in accordance with the informed consent document. However, general information can be disclosed.

Demographic information was compiled from the US Census Bureau State County Quick Facts website and can be viewed as Table 1. The population estimates published by the US Census are for the 2007 calendar year. Names of counties and law enforcement departments have been withheld to help protect participant identification.

Oregon is a state with drastic differences in geography, and the people who reside in different locations also tend to differ in their concerns, priorities and attitudes related to criminal activity. For example, the concerns and priorities of people who live in the Willamette Valley tend to be different from those who live in the high desert plains of Southeast Oregon, or from those living along the coastal region because of differences in occupations, religions, social values, political interests, and other personal and group aspects. The greatest population density in Oregon is within the Willamette Valley, and this population trend impacts social and political attitudes. Statewide national election outcomes reveal voting patterns to be more liberal in this area (Leip 2004). In comparison, locations outside the Willamette Valley tend to be less densely populated, with more conservative voting patterns (Leip 2004). Voting information from the latest national election, attained from www.uselectionatlas.org, reveal all but one research site was located in conservative, rural counties. The other site was in a liberal, rural county. ${ }^{1}$

Eight different cities and towns in Oregon were to host the ethics and racial profiling 
training seminars, however due to low response during pre-registration in one of the locations, that seminar was cancelled. Therefore, 7 city police departments hosted the training seminars under review for this project. Each seminar was devised as a regional training, welcoming officers from surrounding area departments to attend. Venues for the training were picked so that video portions could be presented, while accommodating a group of 6 to 20 officers.

The seminars were led by Oregon law enforcement personnel representing both genders and with white ethnic backgrounds. Three instructors ( 2 male, 1 female) were trained to give the seminar and at least 2 were present at any one session, one from each gender. One exception is noted: for the final 2 sessions: a female substitute from the Oregon Department of Public Safety Standards and Training (DPSST) filled in for the female instructor. The instructors were all active sworn personnel with the rank of; Patrol Officer, Sergeant or Captain.

\section{Participants:}

In total, 68 officers attended the training seminars. Of these, 66 were male, or 97 percent and 2 were female, or 3 percent. Information regarding race of the participants was not specifically gathered but, based on observation, 2 people-of-color, or 3 percent, were in attendance at the trainings, with the remainder being white. Information regarding attendee's socio-economic status was not gathered primarily because, previous research indicates, it is not influential in determining prejudice (Oliver and Mendelberg 2000). All survey and interview participants were white males and ranked either: Patrol Officer, Detective, Sergeant, or Lieutenant. Participant experience as a member of the police force ranged from 3 to 25 years. 
For separate research not primarily associated with this project, every officer (68) in attendance was given the initial-assessment survey by the instructors of the training before leaving the site at the conclusion of the training. At the time the surveys were handed out, the officers were asked to anonymously fill out the survey and turn it in before leaving. They were verbally informed that their feedback on the survey was of interest to the Portland State University Criminal Justice Department as well as the Law Enforcement Contacts Policy and Data Review Committee, (LECC). The final page of the survey contained a brief statement inviting the officer to talk with a researcher, myself, from Portland State University, in a follow-up interview.

The participants in this study are limited to the officers who chose to be interviewed during the interview portion of research. Of the 68 surveys handed out, 45 were returned from all of the seminars combined. Of those 45 returned, 22 officers provided contact information for the interview phase of the research. Once the pool of possible research participants (22 surveys with contact information) was identified, a month later a formal research invitation and informed-consent form for this research project were mailed to each officer. Each officer was instructed to sign and return the consent form in a provided, selfaddressed, stamped envelope if they decided to be part of the study. The research invitation specifically requested the use of their initial-assessment survey data and invited their participation in a follow-up telephonic interview. Eight informed consent forms were returned, eliminating 14 potential participants from this study. One participant was unable to be reached leaving the total number of participants at 7 . 


\section{Procedure:}

\section{Seminar:}

Between 6 and 15 officers attended each training seminar. Those in attendance were not necessarily there voluntarily; one participant disclosed that he was assigned the training by a superior officer, not for reasons of discipline, but rather to help support the training. Snacks and coffee were served in the morning and lunch was catered, but not mandatory.

Each seminar started in the same manner at the same time each day - 9 AM. Once time was allowed for all the probable attendees to arrive, a brief introduction was given by those present, including the instructors and myself. My role was to act as a participant / observer and I disclosed this role to the attendees during introductions. The officers were to give their name, rank, duty, department, and years of experience. Once completed, a warm up game was played where attendees were split into groups of 3 to 4 persons each. The task in the first round of the game was to identify as many different types of plants that were projected onto a screen in a 5-picture-by-5-picture grid. The groups were given a few minutes to complete the task and then answers were compared with each group and tallied by the instructors. The final round of the game was similar, however, first letters of common product, brand-name logos were simultaneously projected on to the screen, 26 in total, one for every letter of the alphabet. Then their answers were compared and tallied. Without fail, all groups had an easier time recognizing the logos than the plants. The object of this game was to illustrate that our culture emphasizes artificial qualities and characteristics over natural ones.

After this activity, a short film was viewed called "The Lunch Date". The film is an exercise in how people can misperceive others based on their appearance, situation, and 
location. In brief, the film is an essay following a white, female senior-citizen's trial getting home from a shopping trip and running into people of various racial and socio-economic backgrounds, in a busy train station. The film was stopped in the middle by the instructors to process the group's insights and what they saw in the film at that point. The seminar attendees discussed the film with the instructors once it finished.

The final and longest portion of the training then began. This portion of the training involved an interactive CD-Rom role-playing exercise in ethical decision making, for which the training was named "Tactical Ethics; Perspectives in Profiling". The officers in attendance were to role play three different characters in the same storyline; a second-year officer, a fifth-year officer and a veteran sergeant. The scenario's setting is a fictitious community dealing with a recent pattern of violent attacks against women in public where the community's Muslim leaders have made some culturally insensitive comments regarding gender.

For this exercise, the attendees were brought back into their earlier groups. As each of the characters was played, different ethical dilemmas were encountered. At multiple points in each character's storyline, the officers were asked what they would most likely choose to do if they were actually in that situation, out of a few given choices. Once the groups discussed the options internally, they were asked to share and compare with their peers and then an overall decision was made. The CD-Rom played a different set of outcomes and consequences for each choice made. Said differently, each decision led to a different path in the storyline for the character to take. Along the way given the groups decisions a few evaluations of the officers' ethical judgment were presented with a final evaluation once the character's story closed. Typically, one entire character was played 
before breaking for an hour lunch. After the break, the remaining two characters were played. This portion of the training took about three hours to complete, not including the hour lunch. The seminar lasted about 6 hours in total. I was present for the trainings and participated within them.

\section{Field Notes:}

I took notes immediately following each of the 2 seminars I attended in reflection of what I experienced and observed. General observations noted were number, race, gender, experience, rank of officer in attendance, as well as notes regarding insightful discussions, conflicts and resolution of differences between officers, instructors and among both. These notes were incorporated into my data analysis and will be explained in the up-coming data analysis section.

\section{Instruments:}

Survey:

To reduce the rate of attrition, immediately following the seminar, all the officers in attendance were asked to complete a copy of a self-administered assessment survey. This process took the officers about five to ten minutes to complete. The survey's cover page consisted of a brief half page statement explaining the purpose of the information sought (feedback for possible improvements), the importance of the information, what the person would receive for doing the survey and follow-up interview (enter raffle for an iPod music player), that their answers were confidential, and they could speak to the Criminal Justice Department contact at Portland State University with any questions. The survey instrument was devised to retrieve information about the officers' thoughts and their assessment of the training before, during, and after attending the seminar (See Appendix A: Sample Survey 
Instrument). This survey consisted of five open-ended questions and seven 10-point scale items. At the end of the survey, participants were invited to disclose their name and contact information for the follow-up interview, as well as self-descriptive data, including age, rank, and gender.

The primary purpose of the open-ended questions was to collect data on the participants' reasons for attending the day's training and to acquire insight into their attitudes and perceptions of the training before attending. Answers to the 10-point scale items were given in numerical form where " 1 " meant strongly disagreed and " 10 " meant strongly agreed. The procedure in this section of the survey asked the participants to answer how strongly they agreed with a single given statement.

To maximize completed surveys and to hold the attention of the participants, the number of survey questions was kept to a minimum. All seminar attendees were instructed to turn their survey in as they left the training. Administration of the survey was selfdirected and voluntary.

Interview:

After the completed surveys had been gathered and reviewed, participants who gave contact information were sent a letter introducing the current research as a follow-up study gathering data related to the training experience impacting their perceptions of people-ofcolor. An informed consent form was attached with instructions to sign and return it with a phone number where the participant could be contacted. The letter and consent forms were mailed with self-addressed, stamped envelopes for ease of return. If the officer had not responded within two weeks, a reminder email was sent re-extending the offer to participate and instructions to sign and return the consent form. If the officer returned the consent 
form, I contacted them to schedule an interview at a later time, convenient for both of us.

The interview schedule consisted of eight main questions with appropriate follow-up inquiries for clarification and to attain depth of response (see Appendix B: Sample Interview Schedule). The interview was broken into two sections. The first section consisted of six questions to assess aspects of the training content each participant had retained since attending the seminar, once having the opportunity to return to work. Data from the questions from this first section were primarily used to help answer the research questions of interest to this study. I was advised to not ask direct questions regarding personal biases of the participants because of the controversial nature of the topic and fear that direct questions would inhibit participation in the study. In the coming Data Analysis section, I will explain why certain survey and interview questions were used to answer the research questions. The other section was a set of questions to assess what they thought of the training format, method, and instruction since attending it. A catch-all question was asked at the end of these sections to access further insight into this topic that may not have been addressed in either phase of the research project. Previous research informs us that the police subculture can be very exclusive (Holmes and Smith 2008), therefore the interview questions were purposefully non-confrontational, to enable greater disclosure and to help compensate for my status as an outsider to the subculture.

The first interview was completed in early July 2008 and the final interview was completed in late September of that year. Interviews were conducted over the telephone which complicated some of the schedule coordination. The interviews lasted no longer than thirty minutes. All interviews were recorded to micro-cassette tape for accuracy with the participant's knowledge and consent. I phoned the participants from my home in privacy. 
All participants were interviewed during daytime hours. Five of the officers were interviewed while at work, with the others choosing to be interviewed off duty. Where the participant chose to be interviewed was at their discretion. Seven interviews in total were conducted.

\section{Quantitative Methodology Rationale:}

A self-administered survey was employed to collect data from the officer attendees to assess their preconceptions and value of the training immediately after the seminar. A survey was advisable for a few reasons. First, it fulfilled, according the CEDP model, the Reaction level of evaluation as described by Glenn et al. (2003). Second, the topic was of a sensitive nature. Participants could quickly, privately, and quietly give answers to the survey items presented, enabling ease of disclosure. Third, collection of statistical data was advantageous to provide descriptive analysis of the participants as a group. Finally, the communication style of police officers is said to be short and to the point. Consequently, it was advisable to mirror this quality in a survey rather than conduct interviews or focus groups which might annoy and alarm potential participants.

\section{Qualitative Methodology Rationale:}

Because the pool of possible participants was small, qualitative depth of the data was essential to increase project validity. Due to the sensitive and personal nature of the topic, individual interviews were best suited to increase the potential for greater self-reflection and disclosure, while minimizing the potential for social-desirability error. Furthermore, if an officer/participant sought to disclose a strong opinion about a colleague, they could only do 
this in a private interview without facing disapproval from their peers, as might be the case in a focus group type setting.

\section{Data Analysis:}

Data were gathered from the assessment survey and the interview schedule then matched with the appropriate research question(s). No questions from the survey's openended questions were used to answer Research Question (RQ) 1 (See Appendix A for details). Questions 5, "The trainers and content matter challenged my opinions about race and police," and 6, "The training seemed 'watered down', meaning it didn't confront the difficult issues of race, police and bias," from the survey's "10-point scale” questions, though, were used to answer RQ1. These two items ask the participant's to reflect on the training's ability to impact officer perceptions of racial minorities. From the interview

schedule, (See Appendix B for details) questions 2c, , "Since going through the training has it changed the way you interact with or perceive members of racial and ethnic communities?", 3, "On your survey you put down that you (agreed, disagreed, were middle of the road) that this training seemed "watered down" in that it didn't confront personal biases toward racial and ethnic minority groups - Do you still agree with your assessment? and 6, "Do you think this training can help officers be more willing to confront ethical issues in their department? Why or Why not?" were matched to answer RQ1. Note that these questions are not direct which was intentional. I was aided in the development of these questions by faculty in the Criminal Justice and Criminology Department of PSU. These questions were asked so as to gather more information about each participant's perceptions of racial minorities without putting them in a defensive position and risk loss of data. These questions most directly 
address the participant's thoughts about the training's impact on their racial minority perceptions having had time (1 month) to work in their community afterward. The corresponding survey questions to RQ2 were from the open-ended section questions 1 , "Please tell us the principal reason or reasons you participated in today's training?", 2, "As you prepared to attend this training today, what did you think the training would be like or about?", and 5, "How do you feel about the importance of this training for law enforcement officers?" These questions invite answers that help describe the officer's reasons for attending the training and reflection upon their thoughts regarding the training content as they prepared to attend it. From the interview schedule questions 1, "Now that you have been through it what do you feel the objective of the training was?", 2a, "Since going through the training have you thought about your department's organizational culture or ethical issues in law enforcement?", 4, "How do you think your fellow officers would feel about attending this training? Why?" and 5, "How do you think your fellow officers would respond to this training after attending it? Was your personal response different?". Those matched to help answer RQ3 were the same as those for RQ2. This is possible because the questions were non-leading.

Data from each participant were coded by hand by myself without using coding software. Each participant's answers were compared with the tenets of Whiteness Theory as well as the findings from previous studies in the review of literature. I used the following outline when coding the data.

White privilege:

- is normalized to the point that whiteness becomes the standard to reach for all people in the culture,

- is mostly invisible to whites because it is normalized, 
- and because it is invisible, whites are enabled to avoid directly addressing the structural racial inequalities within society, thereby perpetuating those inequities and the privilege itself.

Analysis of the field notes were figured into answering the research questions and used to aid in discussion of the data. Then the collected data were analyzed for reports from the participants that the training had impacted their perceptions of people-of-color.

\section{Researcher Bias:}

Before presenting the data, an examination of my biases toward the subject require attention. In order to maintain validity of qualitative research, it is imperative that the researcher address areas of personal bias in relation to the topic. In the present case, I became interested in this topic because I have a personal history of bias against people-ofcolor. This bias has been in remission since my undergraduate college experience where I was exposed to other points of view in my scholastic studies as well as my professional experience where I was able to work along side people-of-color. As I uncovered my biases and some of our culture's historic and present oppression of people-of-color, I became frustrated by my own and other's denial and minimization of their experiences. This reframing of my ideology compelled further inquiries into the experiences of people-of-color of which this project is born from.

It is my position that a clearer image of the truth of social interactions can be revealed, but not always, from those outside the cultural mainstream. This position, based on racial ascription, is taken here because people-of-color have had to constantly relate to white people in this society and the distorted views of them, based on the largely negative stereotypes communicated and perpetuated through socialization and enculturation. U.S. 
population statistics show greater support for the likelihood that, in their daily errands, a white person may interact solely with people of their same racial background than the likelihood of a person-of-color is to do the same. In general, white's degree of proximity to The Other - in the present sense, people-of-color - and the messages whites receive through socialization about "them" is distorted in the white experience, if left unchecked through experience and education. Durham and Wilson (2008) note, for instance, in cases where all factors are equal (e.g. financial status, gender, class, sexual orientation), racial minorities, especially blacks, are stereotyped as "dirty" and "lazy" in comparison to whites. Behaviorally, blacks are regarded as "disinterested in keeping up property" and “...disinterested in work". Because of the proximity issue, it is more likely that a white person will develop and adopt a stereotype of people-of-color more inline with what the dominant culture transmits.

My frustration with the perspectives white people possess of people of color, leads me to identify the institution of the police as a force, on some unconscious or conscious level, for the maintenance of the racial status quo. Through my experience studying this topic and having the opportunity to talk with members of the police, I have come to a better understanding of their position and am able to place their perspective in context to their own social pressures and limitations. Officers I have talked to personally report the level of stress put upon them, from physical threats, to feelings of being overworked and undersupported, to frustrations with judicial limitations affect how they work with the public. Based upon the findings of previous study regarding the normalization of racial bias within our culture (Altman 2000, Perry 2001, Armour 2008), the implications of interactions in racially charged encounters within a multiracial community could be amplified numerous 
times depending on the animus felt between racial groups and the police.

I approach this project critical of the police because they possess great power over the citizenry and because they are the primary gatekeepers to the criminal justice system. However, this is tempered to include the experience of police officer from what I have learned during this project. This was the intent of this research; to identify participating officers' self-reported perceptions of people-of-color and then explore the impact of attending a recent, state-of-the-art, anti-racial profiling training on those perceptions. 


\section{CHAPTER FIVE}

\section{FINDINGS}

Thus far, this project has examined racial profiling as a problem for law enforcement and how anti-racial profiling trainings challenge an average law officer's perceptions of people-of-color. After my discussion in the last chapter of how the present study has been constructed to examine those perceptions, I now turn to introduce the data gathered from the post-training survey, field notes and follow up telephonic interviews with police officers from different locales in the state of Oregon. The participant sample totaled 7 white, male, sworn police personnel, although the invitation to participate was not restricted by race or gender. The research involves the feedback and perspectives of 1 "Line Officer", 1

Detective, 4 Sergeants, and 1 Lieutenant. Their law enforcement experience ranges from 3 to 25 years. During the telephone interviews, all participants were informed before the interview began that they did not have to answer any question they were uncomfortable with and their answers would be held securely and reported confidentially by myself . Furthermore, participants were not instructed to be in any certain location when interviewed.

This chapter is focused on answering the proposed research questions regarding officer perceptions of racial minorities and if police officers report the anti-racial profiling training impacting those perceptions. The collected data were recorded onto audio tape and transcribed by myself. Then, using the printed transcriptions, I coded the data by hand, without using coding software, according to the tenets of the theoretical foundations used in this study, e.g. Whiteness theory (See Chapter 4, for reference).

In general, the participants answered that they related to racial and ethnic minorities 
as individuals, rather than a set of cultural stereotypes, and the training did not impact their perceptions because they said they did not adhere to those negative cultural stereotypes to begin with. The following sections present the data as they address each of the research questions. I have chosen to present research questions 2 and 3 first because they address preconceptions of race, and are preliminary in scope to the greater aim of this project, followed by the central research question, question 1 pertaining to the training content's ability to impact those preconceptions. Data which affirmatively answers the premise of each question is presented first followed by data that negatively answers the premise. Research question 1 is presented differently though. The addition of field note descriptions of the sites and training activities and reactions help to put the training in context so they can be more fully critiqued for their potential impact on the officers' perceptions of racial minority members. Answers to the relevant survey and interview questions are summarized after the presentation of the data associated with each research question.

\section{RESEARCH QUESTIONS}

\section{RESEARCH QUESTION 2:}

Do police officers from the state of Oregon report having held a personal bias against racial / ethnic minority community members before attending a racial profiling training?

The question seeks to shed light on whether police officers have viewpoints of racial and ethnic minority communities which could be perceived as prejudiced and biased. Considering my position outside the police subculture, asking the question in a straight forward manner would presumably elicit silence, withdrawal, or an answer of questionable 
validity. Therefore, the difficulty in posing such a question lies in the assessment of responses from multiple questions. As covered in Chapter 4, the questions from the initial assessment survey used to answer this research question were, from the open-ended section questions 1, 2 and 5 (See Appendix A for details). These questions invite reflection upon the participant's thoughts regarding the training subject as they prepared themselves for its attendance. From the interview schedule, questions 1, 2a, 4 and 5 (See Appendix B for details) were also used to answer this research question. Again, the interview questions used are intentionally not direct and non-leading so as to maximize data collection regarding racial perceptions and bias and minimize the risk of loss of data due to potential for uncomfortable sense of critical judgment.

\section{$\sim$ Affirmative Responses}

A clear and consistent answer to research question 1 was not attained directly from the participants in this study. Reports did emerge that other officers may be racially biased as noted by the comments of two participants regarding a few of their peers. Examples of this can be found later, under the negative responses to this question, especially when discussing the strength of one participant's response about a colleague who will "say a lot of racial things". Participant $C$ recognized the jokes about racial minorities told within his department look bad form a critical perspective, suggesting he is aware that race is an issue within his work culture.

Participant A illustrates the officers who need this training, or some experience to expand their perceptions of race, were those in one of two camps. He describes both as being avoidant of it for different reasons, as described in this supposed internal monologue: 
'This isn't for me because I don't have this issue, so why would I attend' ... Or you could have the rogue out there that says, "You know, I know what is going on out in the street and I don't need anybody to tell me. All it does is inhibit people's efforts. And so you know 'why would I want to attend this training?'

According to the tenets of Critical Whiteness, elements of whiteness are evident in this passage because each of the hypothetical officers appears to reject the possibility that they might hold a prejudice. According to Participant A's reflection on those peers reluctant to attend these type of trainings, the officers in the first camp may be "doing whiteness" through their, most likely, unconscious denial of privilege and status. Those in the second camp would appear to reflect a more conscious and active form of it. For example, during his interview, Participant $C$ noted the following when asked if the training affected the way he perceives members of the racial minority community:

Personally, I don't believe - I don't see myself as somebody that's got bias or issues along those lines.

This response is nearly verbatim the hypothesized internal monologue Participant A indicated. Moreover, the denial of his bias indicates a privilege; the privilege of being unaware. McKinney (2000) and other White Studies scholars would argue that this is a case of white privilege and denial; the denial of one's own potential for bias. Recall Altman (2000) and his proposition that we all have the potential for bias due to our culture's method of socialization, and we come to realize our practiced culture conflicts with the ideal standards set forth in the $14^{\text {th }}$ Amendment, guaranteeing the right of equal protection. According the data, this may cause some cognitive dissonance within these participants as they negotiate the ethics of their work culture. However, according to similar studies 
conducted internationally, it is unlikely any society has attained similar benchmarks within their own culture. All of the participants to this study reported self perceptions of their biases most like the first hypothetical officer, while there were no self reports of reluctance to attend because the participant thought they knew "what is going on in the street" or everything needed to know about ethical training and anti-racial profiling.

In addressing the attitudes of their peers, a few participants mentioned that some of their fellow officers may hold perceptions of members of racial minorities incongruent with the parameters of the $14^{\text {th }}$ Amendment. For example, Participant E mentioned:

I think this training would help a couple officers that we have. We have one I'm thinking about hitting with a $2 \times 4$ because he never seems to think before he speaks. He'll say a lot of racial things...

This disclosure illustrates that, indeed, some officers may have prejudicial views of peopleof-color. Participant E did not expand on what this fellow officer has said explicitly, but it was apparent from his strong opinion, "hitting him with a $2 \times 4$ ", that he considered it a significant problem. In fact, he went on to state, “... we've had an official conversation about that already" in regards to this same officer, indicating superiors were notified of this peer's speech behavior.

\section{$\sim$ Negative Responses}

Other participants reveal that this training is typically avoided by their fellow officers. They noted that their colleagues would be "reluctant", "skeptical", or carry "an attitude" into such training. However, as the data revealed, this is not because officers have personal biases per se. Rather, it is because this training is typically regarded as not actively engaging 
and regarded as boring," dry", "a long day of training" and not fun. From the data, it is clear that these types of trainings are avoided because their experience with them have been in lecture format i.e. passive, not engaging, and non-interactive.

\section{$\sim$ Summary}

In summary of this first research question, all participants, as individuals, reported to carry no negative perceptions of racial and ethnic minorities. A few participants disclosed that some of their peers do harbor cultural insensitivities that in some cases require official attention.

\section{RESEARCH QUESTION 3:}

Do police officers from the state of Oregon express having held a perception of members of the racial/ethnic minority community as individuals prior to attending a racial profiling training?

The following findings come from data attained through the responses to the openended section questions 1, 2 and 5 (See Appendix A for details). Again, these questions invite answers that help describe the officer's reasons for attending the training and reflection upon their thoughts regarding the training subject as they prepared to attend it. No items from the "10-point scale" questions were used to answer this research question. From the interview schedule questions 1, 2a, 4 and 5 (See Appendix B for details). These questions are purposefully not direct. They were developed so as to gather maximum information about the impact to their perceptions and minimize the risk of loss of data. 
$\sim$ Affirmative Responses

All of the participants in this study reported to hold no negative bias toward peopleof-color prior to attending the anti-racial profiling seminar under review. Participant A best articulated his stance regarding racial prejudice in the following passage from his interview: "I don't know. Maybe the training wasn't a lot out of line from what I was thinking." He went on to note that the training "reaffirmed" his perceptions on race rather "than challeng[ed]" them. Consensus of a positive perception of people-of-color as a whole before attending the training is evident. Participant $G$ responded to the same question with this description of his perception of racial minorities.

Well, being - I've grown up throughout the United States. I grew up in several different places and - I was also in the military so I've had the opportunity to interact with persons of different cultures and ethnic backgrounds and it's never been a real issue with me as long as the person is good-hearted ... you know and they're a decent person, then it doesn't really matter to me what they look like or what color their skin is. So I'm pretty much used to dealing with persons of different backgrounds and different religions.

Such a disclosure reveals the strongest support for the research question: that officers from Oregon see people-of-color as individuals rather than the stereotype of that person's ascribed racial or ethnic label. Evidence of this appears in his evaluation of whether a person's character is "good-hearted" and "descent".

Participant D touched on an interesting concept regarding the controversial nature of this topic among police officers. In a general way, he noted that police officers would be less likely to open up about this topic as individuals, for fear of looking foolish to their fellow officers. "... anytime you see something that talked about groups and participation, 
people get a little...... little antsy." He likens this phenomenon to the experience of high school to clarify:

Well anytime you got to do more than just sit there, people are sharing your thoughts and views, you know whatever, you don't want anybody to ever, I guess, thinking you're... just like you being in high school, no one wants to look stupid...

This suggests that especially in a training seminar, discussing a controversial topic, the attendees may be hesitant to reveal their inner thoughts to their peers, for fear of appearing ignorant on the subject. In itself, this is noteworthy because it suggests a present desire of the officer to be well-versed multiculturally, and although the officer may feel ignorant, he has espoused the ideals of equitable relationships within the community. This is a positive beginning. Though, given the knowledge of unconscious denial of privilege it may be that even though these officers hold racial equity in high esteem they may be unaware of their own biases or perhaps not willing to admit to them.

\section{$\sim$ Negative Responses}

From field notes made at one of the training seminars, the group setting may be beneficial for officers with controversial positions on this topic. To illustrate, in an important interaction between two attendees, as the interactive portion of the training began, one officer offered a myopic and somewhat negative perspective regarding racial minorities in his community. This officer's perception was challenged by another who called his position "narrow-minded". The instructors attempted to ease the confrontation of the accused officer, but he offered only a few limited contributions to the training from that point forward. Although this officer was challenged by his peer, it appeared to have the effect of 
substantially limiting this officer's participation in the training. If this officer held a biased perception of people-of-color, one of two possible outcomes occurred; 1) his attitude, thoughts, and perspectives were suppressed and kept silent, or 2) the challenge let the officer with the questionable perception know that not all of his peers shared his position. But again, if this officer held a bias against people-of-color, the power of one's cumulative socialization within a group outpaces that of one confrontation from a peer. Repeated interventions from peers and superiors may be necessary to overcome a strongly held perception. Unfortunately, it is unknown if the confronted officer's perception had been impacted by the peer interaction because of my blindness due to the telephonic interview method.

$\sim$ Summary $\sim$

In summary of the above data that answers research question 2, the participants reported their perceptions of people-of-color were positive. The only negative response came from an observation of a training attendee who offered a myopic understanding of police -race relations and was challenged by a peer. So it appears that more research needs to include and attract officers to ascertain whether there are a wider spectrum of divergent viewpoints among law enforcement personnel.

\section{RESEARCH QUESTION 1:}

Do police officers report their perceptions of racial minorities being impacted as a result of participating in a racial profiling training seminar? 
The first training attended occurred in "The Community Room" of the host department's City Hall; a large "L"-shaped room likely used primarily for community social purposes. Dimensions of this space measured at their greatest length about $50^{\prime} \times 50^{\prime}$ with a 20 ' ceiling. There appeared to be a small kitchen space around the corner within the room. Several large 7 foot tall cabinets were pushed against the longest side of the room likely used for storage as there were other boxes stacked beside them that appeared to hold decorative items and supplies for activities. There were two large rectangular windows along this same wall that were undraped. Sunlight from the summer morning shone into the room, the temperature was mild and comfortable and a door at the back of the room was open to a large, grassy area and a distant, empty playground. A catered lunch of sub sandwiches, a salad, cookies and a variety of soft drinks, juice and water was made available at the back of the room by the kitchen area, but in the morning coffee, tea and coffeecake were made available in the same space. Three instructors were present; a white, male retired (due to work-related injury) former Detective who used a wheelchair for mobility, a white, female Captain from a police department in one of the major cities in Oregon, and a white, male Patrol Sergeant from a Sheriff's office within the Willamette valley. Fifteen officers attended the training that day plus myself as a participant-observer. All officers were white males except for one who disclosed in his introduction he was a member of a nearby tribal police department and one white female officer. A laptop and projector sat on a folding table at the front of the room. The space between the table and the wall-mounted screen where the projector faced is where the two able-bodied instructors stood on each side of the projected images of the training content. Seating was arranged in a rectangular fashion so that all attendees could see their peers across from them but not those to the sides without bending 
forward or back in their seat. I arrived just as the instructors were starting and took the only open seat at the "front" of the room which was on the end of a line of seated officers. The retired Detective took notes on a laptop just across from me at the other end of the seating arrangement.

The second training I attended took place in large room in the Sheriff's Office building in the Host department's town. Dimensions measured roughly 25' wide by 40' long and with a $15^{\prime}$ ceiling. This room appeared to be used for training purposes and also had storage cabinets against a wall and windows positioned high along the entire length of the outside wall. It was also summertime and the temperature in the room was comfortable. The training equipment, i.e. tables, chairs, screen, laptop and projector were at the far end of the room with one table at the other end where the catered lunch of sub sandwiches, a salad, cookies and a variety of soft drinks, juice and water was set up. Seat arrangement was similar to the other session I attended however only 8 officers were in attendance making myself the 9th attendee and making it possible to sit in an arcing arrangement rather than the rectangular setup of the other session. Again I sat on the end of the line of officers. Two instructors were present at this training and both were different from the previous session; One was a white male Patrol officer from a department in a large metropolitan city in Oregon, the other was a white, female Captain who worked in the Oregon Department of Public Safety Standards and Training and was onsite as an alternate instructor for the female officer instructor who was not available that day.

At the first session I attended, the officers appeared engaged in the training content but appeared reluctant to give opinions or insight from personal experience and discussions consequently appeared to lag and several instances of awkward silence occurred. 
Furthermore, the instructors appeared unprepared to foster discussion among these officers. For example, at the end of the framing exercise at the beginning of the training day where the officers were to identify as many plants and then brands as possible, the female instructor asked the group their ideas about the purpose of the exercise which elicited no response. Instead of probing the group for ideas and facilitating a meaningful discussion with which the officers could approach the subject, all three instructors stated the purpose and moved on to the next activity, missing a chance to establish within the officers a grounded relationship to the training content. The purpose of this exercise was for the officers to recognize that natural variation, as in the case of the plant identification, is often overlooked for its static existence but that manufactured variation, in the case of the brand logo identification, was an easier task because of cultural pressure in the form of repeated exposure through advertizing which often has a dynamic existence.

During the lunch break at this first training experience, I made attempts to talk with the officers and instructors in an effort to build rapport and interest in my research. During one exchange I asked the instructors how the previous session a week or two earlier in another part of Oregon had gone. The instructor that answered, who happened to be across the room, said the session had been well received and gone smoothly and then began to critique the way the officers in that previous session had decided to answer some of the ethical questions in the CD-Rom activity as if the officers had not answered "correctly". This disclosure made me, as an outside observer, feel uncomfortable for 2 reasons, 1) because it appeared highly judgmental and 2) because he was across the room, everyone in the room was privy to his opinions. I could see some of the other officers near me paying close attention to his comments and quietly return to their conversation with their peer. I 
disengaged conversation from this person quickly so that I could reduce any perceived association with him among these potential research participants. This interaction may have had a chilling affect among the officers that paid attention to his comments in regards to their level of participation in the remainder of the training. Considering the controversial nature of the topic under review in the training, i.e. racial profiling and subtextually, racism, it seems these attendees would not want to feel like their honest answers are being judged by the training leaders. Perhaps to reinforce this, later, when I conferred with my contact in the Criminology department at PSU he informed me the instructors thought this training experience had been more difficult than the previous one because the officers were harder to engage in discussion.

During the second training in which I attended, I noticed a significant lighter mood in the room. Only one female officer attended but there appeared to be no officers-of-color present. Officers appeared to know each other to a greater degree and had built long close relationships with one another than in the previous session. For example, one of the officer kidded with another during the introductions for being a former firefighter, opening my vision to a casual rivalry between the 2 civil service institutions. They also granted me partial access to the group when I disclosed the years of graduate school I had experienced at the time as if that was a level of genuine police experience. The instructors at this training appeared more adept at facilitating discussion among the officers and brought in a greater breadth of situations in which an officer's ethical decision making skills might be tested. Although, they also missed the chance in the opening activity to bring into focus a deeper meaning from the exercise in relation to ethics, race and racial profiling behavior. Discussions may have been easier to facilitate because of the familiarity the attendees 
appeared to have with each other but also because the instructors asked more probing questions of the officers to assist them in disclosing their experiences, insight and opinions than in the other training seminar I had observed. The larger group discussions appeared to be dominated by the male officers in the room. In fact, the female officer in attendance appeared soft-spoken, reserved and spoke more in the small group discussions. The officers appeared to speak to the concrete details of ethical decision making and the parameters in which they work without much, if any, editorializing or grandstanding moral testimonies. Because the instructors helped to focus their attention on the curriculum, it appeared to help keep the officers engaged in the topic. One of the major points of the training was familiarizing the officers to the difference between criminal profiling and racial profiling as well as how to use criminal profiling to remain active policing agents when police-race tensions rise.

Data collected during the interview revealed this point was not lost on some of the participants. Speaking to the notion that racial profiling trainings have been "watereddown", a few participants touched on the concept of "de-policing" (i.e. passive policing, such as only responding to complaint calls). For example, participant $G$ generally stated that his perceptions of racial minorities had not been impacted. Reflecting on the difference of his perceptions of people-of-color resultant of his attendance at the seminar:

I don't think it's changed, but it's definitely, you know, kinda pushed it more to the forefront. Definitely take a more active role as far as making sure that, you know, when you deal with people that you always handle things appropriately.

Likewise, Participant F expands upon de-policing through his personal reflection of his training experience: 
I think it may have emboldened me a little bit because I think, like many people, I was a little, you know, a little hesitant once the term racial profiling came up or the discrimination by itself.

If officers are trained to follow the rule of law and still police the community, they are presumably active agents in their department and implicitly advocate for their peers to avoid the urge to "de-police" during the course of their work. As suggested by their comments, these participants may have been unclear in the past regarding how they were to work with people-of-color as a result of other anti-racial profiling training they had been part of.

Turning now, in more detail, to the collected data from survey and interview methodology, recall from the description of the analysis phase from Chapter 4, no questions from the survey's open-ended questions were used to answer Research Question 1. However, questions 5, and 6, from the survey's "10-point scale" questions, were (See Appendix A). These 2 items were asked of the participants so they could reflect on whether or not the training impacted their perceptions of racial minorities and how it did so immediately afterwards. From the interview schedule, questions 2c, 3 and 6, were matched to answer Research Question 1 (See Appendix B). These questions directly address the participant's thoughts about the training's impact on their perceptions of members in racial minority communities 1 month afterward.

Data from the assessment survey associated with impacting officer perceptions were collected (See Appendix A to review the 5 open-ended questions). Charts 1 and 2 present the data related to how the training impacted the participants based on the 2 closed-ended questions from the survey related to Research Question 1. The following section first discusses participant responses which affirmed the training's impact to their preconceptions 
followed by those answers to the survey and interview questions that support a negative response to the question's premise.

\section{$\sim$ Affirmative Responses}

Of all the participants in this study, 2 (29 percent) initially expressed a greater impact to their perspective about people-of-color than the rest, suggesting some degree of gained insight. They said:

I think it addressed realistic issues and it allowed for whole interaction. We could discuss in our groups and there were different opinions. And it kinda promoted different opinions from different people, from different agencies, [to] know what everyone else has experienced.

And:

We dealt with, you know, we talked about racial bias and the different scenarios, I know you're trying to prove a point with each one, and I thought that was good. It ... I didn't think it was vague. You know that's what I would say "watered down" as, as vague or...indecisive.

Participant D added, the way in which the training was presented made the group discussions conducive to open disclosure among the officers. He noted:

I mean, it's the way it was presented, it was put together. It was actually really interesting, the group setting stuff, and ended up being really productive having it...

From this, "being really productive...", we can deduce the group setting, as it was structured in the seminar, allowed the officers to risk disclosure of their personal views on race and ethnic relations, however positive, negative, or neutral they may be, with a good chance of being supported positively by their peers. 
However, as Barlow and Barlow (1993), who found trainings that were the least confrontational toward racial bias and more easily palatable are the trainings that receive the highest praise from attendees in survey responses, may agree, assessments of police-race training would more likely than not return with positive reflections, such as in the above. Critical analysis must explore the totality of participant responses to assess the intention of these officers' reports. Upon further questioning, these participants reported that in some respects the training had not impacted their perceptions of race despite their proclamations that the training was productive.

\section{$\sim$ Negative Responses}

As previous literature would support (Barlow and Barlow 1993), only Participant A and Participant D, equaling 29 percent of the participants, expressed the greatest critical review, (others were critical as well but less so), and gave unexpected responses indicating a negative assessment of the training. For example, their immediate answers to the items in the survey suggest it failed to adequately impact their perception of race and that it inadequately confronted the police-race bias issue. Responses suggest these participants' perceptions of racial minorities were impacted minimally as a result of attending the seminar. To illustrate, Participant A said: “Maybe the training wasn't a lot out of line from what I was thinking. Does that make sense? Maybe as more reaffirming... than challenging." Similarly, he responded a little later that, "It would be like me going to a quit-smoking course and I

don't smoke." Likewise, Participant D reported the training had neither affected the way he interacts with, nor his perceptions of the racial minority community. When asked for clarification he stated: 
Well, I think that, you know, the behaviors and my perceptions of things that I was kinda in line, and so I don't think that I necessarily changed anything as far as dealing with or interacting with... You could just say that it just reconfirmed. You know, the various trainings and then it kinda comes down to the personal values and beliefs, too.

Others in the study said the training had not impacted their perception of people-of-

color, but in the same way they said, like Participant F:

I've grown up throughout the United States. I grew up in several different places and I was also in the military so I've had the opportunity to interact with persons of different cultures and ethnic backgrounds and it's never been a real issue with me as long as the person's good-hearted, you know, and they're a decent person then it doesn't really matter to me what they look like or what color their skin is. So I'm pretty much used to dealing with persons of different backgrounds and different religions...

These responses suggest these participants held to their perceptions of racial minority members and little new material was learned regarding bias. Moreover, the responses inform us that their positive perspectives regarding race and police were supported by the training.

However, Participant E disagreed with the statement regarding the training being "watered-down" in his survey responses. In his interview, he said:

... One thing, in talking with the other guys that went through it, is we would have liked to have seen more scenarios. You know, the guys were just kinda starting to get into it and they said it would've been nice to have a few more to go through, just to kinda challenge them and make them think going down the line. But it - none of my guys had anything negative to say. They thought it was actually a very, very good training. Very positive training.

At first the participant notes the need for more scenarios and the desire for his peers to be challenged so the officers can really embrace the message of the training. Despite his 
assertion that the training was "very good", he appears to state a gap between what the officers wanted from the training and the limitations of the interactive CD-Rom portion of the seminar. Other participants in the study were also able to articulate how the training unsuccessfully challenged their perceptions of race and are presented in the following section.

Participants were asked for their thoughts on improving the training in some way. For some, their answers reflected desire for a further impact upon their perceptions of people-of-color and reveal how, in the following ways, the training could have had more impact upon the participants' perceptions of people-of-color.

- Tone and Format

Along with a few other participants, one disclosed discontent with the manner in which the training was presented. At one point in the interview, he proclaimed the training instructors were too soft in their approach, as noted in the following passage:

... I think especially in a law enforcement aspect you need to - for a training to be impacted, you need to just come out and say what you're trying to say, instead of skirt around the issue. You know, maybe just come out and say, you know, "We know there's racism on all sides, not just, you know; white against black, white against Hispanics, so on and so forth."

However, later, he notes the opposite, when remarking on his ideas on ways to overcome officer hesitation before the training, confusing his position on these trainings:

... I think the class you guys gave was fantastic. You know, it was probably the best ethics class that I've taken. I think maybe you guys maybe should advertise that a little more like, you know, this isn't your typical boring ethics class. It's interactive. It was, in my opinion, non-confrontational unlike some I've been in. 
He then illustrated an experience he had with another police department, where an African American officer taught a cultural diversity training in which he and other attendees felt their responses were assessed over-critically. It appears that this officer endorses a training style that is honest in its address of racial prejudice in the world but notes how officers react uncomfortably when confronted personally.

\section{- Leadership:}

One participant mentioned the content could be improved by including a greater leadership component to increase what attendees could learn. Others remarked on either the structure of the training or the logistics of it. For example, one noted in his recollection of his assessment:

...It just seems a little unrealistic. Especially with a lot of us there, that were Sergeant rank and higher. I mean, we're always dealing with that and we're still responsible for getting all the other things done, too. You know, sometimes you just stay a little later. So I just think that was maybe just too sterilized or scripted.

Another facet of leadership was discussed by another participant, who reported senior staff members are most in need of this type of training. Thus, it informs us of a possible component not adequately addressed in the training: the component of supervision or leadership. The addition of this component could propel an officer, who possesses a controversial perception of racial and ethnic minorities, to question their understandings of the relationship between race and policing. Police officers are trained to gain control of chaotic situations, but when the topic of complacent racial profiling arises it behooves them to put their understandings up to critique as prior research on effective multicultural education supports (Asher 2005; Akinyela \& Aldridge 2003). This is necessary for everyone who desires to understand the world around them. 
- Training Description:

When asked what could be done to reduce the level of skepticism on the topic and reluctance to attend, nearly all the participants remarked on the title and description of the training as being a major barrier to attendance. From the data, "Ethics Training" is a redflag to the officers to be critical and skeptical. They are scrutinized routinely for their interactions with the public, both in the media and in community circles. Ethical considerations in law enforcement, on the job, can seem as a Catch 22 to many officers, as one officer explained in this study. For example, from an outsider's view, either the appearance of skepticism originates from an officer's denial that they have a bias, or the officers think the training will be a waste of time because it will tell them things they already know, thus not challenging or engaging them. The data revealed that, to some extent, both of these can be true. However, the participants reported that for "the typical officer", ethics training means being subject to a dictatorial lecture. A common response was the title should stand out to the officers as being different than their previous experiences with ethics training. The participants also universally noted that the training description could aid in dispelling the reluctance and skepticism many officers appear to have. Although appearing irrelevant to the answer of the research question, it is progress in an incremental step, in that once reservations regarding these trainings can be substantially reduced, negative stereotypes and perceptions can be constructively confronted.

\section{$\sim$ Summary $\sim$}

In summary of the above data pertaining to research question 1, some officers initially state ethics and racial profiling training challenges their perceptions of people-of- 
color while others have neutral perceptions of the training's ability to confront perceptions of race. A few participants reveal that to some degree the ethics training under review here may "break down" reluctance and skepticism many officers have about this type of training with attention paid to three critical aspects of them; conscious attention to the tone and format of these trainings, increased attention to leadership responsibilities, and increased attention to the description of racial profiling trainings, e.g. as different and interactive unlike most ethics trainings officers have experienced

\section{$\sim$ Overall Summary of Research Questions}

In summary, the collected data revealed that although the participants felt they held no bias against members of racial minority communities, they disclosed that a few of their peers might. Because of their positive position regarding racial bias the participants significantly claimed the racial profiling training did not impact their perceptions of racial minorities. However, even in their positive remarks, some evidence of the tenets of whiteness were found throughout participant responses. Participants frequently noted the training was anticipated to be an uncomfortable experience and they thought their peers would also feel reluctant to attend. However, 100 percent of the participants reported they exited the seminar with a positive assessment. The findings addressed critical components of whiteness through the participants' reflections on; awareness and denial of personal bias. Those findings will be discussed in the next chapter. 


\section{CHAPTER SIX}

\section{DISCUSSION}

In this chapter I discuss the implications of the data related to social and police policy, present conclusions, and suggest related topics for future research.

From the previous chapter, the data revealed that the participants reported they had no negative feelings about people-of-color. The data also revealed that some participants were aware of other people in their departments who had questionable behavior and may not be as tolerant of people-of-color as they themselves reported to be. The majority of the

participants reported the training had brought the issues of policing and race back into their awareness, suggesting that they had lost some of the details about racial profiling and ethical race relations between themselves and people-of-color in their community.

Nevertheless, a scholar of critical whiteness would likely find, in their analysis, elements of the tenets of whiteness theory in the data collected. The first section of this chapter discusses the themes which emerged in the analysis of the data. The first is Whiteness in Law Enforcement, as reflected in their comments where they reported the training made them re-aware of the details of the problem of racial-profiling, as well as the unanimous claim to not have a bias related to people-of-color. The second is a unanimous reflection among all the participants these trainings that involve anti-racial profiling and ethics are to be avoided. 


\section{THEMES}

Two overarching themes emerged during data analysis was Whiteness, specifically manifested in comments related to participant re-awareness of police-race relations, and denial of personal bias, and that the training is avoided because it is thought of as a passive, boring experience. The following sections will explore the data related to the themes.

\section{WHITENESS WITHIN LAW ENFORCEMENT}

Whiteness scholars discuss the ramifications and consequences of privilege and denial. The collected data explicitly reveal evidence of both privilege and denial by some of the participants after the racial profiling training designed to empower them to do their work without thinking of people as stereotypes. As I will present, the consequences of these participants' reported practice of the tenets of whiteness suggests that identifying their white privilege remains an obstacle for them and maybe other law officers.

\section{- Re-awareness}

First, I examine participants' re-awareness of the relationship between race and policing. Whiteness is reflected through comments regarding re-awareness because it suggests relations between racial minorities and the police faded from consciousness, a privilege that racial minorities, according to white scholars (Wise 2008, Helfand 2005, McKinney 2000), do not have.

Even though none of the participants were explicitly asked about bias against people-of-color, all participants mentioned that the training made them aware again of the details of racial profiling, which appears to suggest race relations and their implications, over time, get buried under the day-to-day responsibilities of a white male law officer. One 
participant included this assessment of his awareness of the problem of race in his town.

But I'd say no. There's nothing that I've changed other than just - I suppose my awareness is - I'm more aware of circumstances and just try to be more sensitive to other people and other ethnic groups. I guess, I guess that'd be yes... a little bit.

Another way that awareness can affect these officers and influence them not to attend these seminars is revealed in one participant's responses. He said his peers would be "not overly excited" to attend because they had just spent considerable attention on cultural awareness activities in their department for the purpose of accreditation.

In relation to impacting an officer's perception of people-of-color, training outcomes may be more positive if the training accounts for the demands made upon an officer and their required knowledge of legal procedures and their applicability to certain situations. An officer may be more likely to place the nuances of someone's given culture and race at a lower priority status than the more pressing details of standard situations like those that require the protections of the $4^{\text {th }}$ Amendment. Conversely, they may be less likely to forget about the effects of race and culture on their personal style of policing if they are exposed to the concerns of people-of-color repeatedly overtime (Armour 2008; Dunham and Wilson 2008).

\section{- Denial of Personal Bias}

The denial of personal bias among the participants stood as a prominent support for the theme of whiteness within the collected data. Aiding the understanding of the premise of both research questions 1 and 2, the denial of personal bias can be viewed in two ways. First, the participants' denial of bias may be the result of meaningful interaction with, listening to and reflection upon racial minorities, racial minority's perspectives of the 
dominant culture and their own biased behavior and thoughts (Altman 2000, Armour 2008, Perry 2001). It appeared all participants gave responses attuned to this perspective. The other perspective would suggest, like McKinney (2000), Wise (2008), Helfand (2005) and other white studies scholars and activists might, the denial of the possession of racial bias may originate from an adherence to the cultural pressure to move on from our country's period of racial unrest; that our culture is now post-racial.

One assertion seems supported by the data: that bias tends to be expressed as a quality someone else possesses rather than a personal quality. Even the participants who mentioned bias and racism exist did not see themselves as carriers of a bias toward peopleof-color. Unless white people have examined their own lives and whom they identify with in the social world, it is unlikely they would be inclined to notice their biases toward people-ofcolor. This, as explained in Chapter 3, is because the system of race works for whites. They are not under the pressure to examine anything that confronts their privilege unless they want to. "Wanting to" is an example of that privilege. It marks a level of freedom that people-of-color lack: the freedom to be ignorant of another's experience. In this sense, it appears the training under examination here in this research did not impact their perceptions of race about themselves and, by proxy, that of racial minorities.

Although 2 participants (29 percent) explicitly stated the presence of bias within the profession, the majority, 71 percent $(\mathrm{N}=5)$, noted in some form denial of a personal bias among their peers, but rarely mentioned it as a personal quality. Most people, talking to others they have just met, as in the context of the interviews, would probably do the same to give the best impression of themselves. However, bias, as the participants appear to see it, is something rarely possessed internally but visible in others, whether on the part of their 
fellow officers or community members they encounter. Two participants disclosed their assessment of possible bias in a racial or ethnic context in their departments. In another case, one participant gave an example of a personal passive bias, but did not identify it as such.

The inability to process one's own prejudice and bias makes it difficult to enact change inside an organization because the denial of personal responsibility for the issue creates an excuse to not examine one's value set (Asher, 2005; Akinyela and Aldridge, 2003). Real effective change has to be internalized first in order to be broadcast (Asher 2005). The reasons for this seem obvious. If someone stands up to a group and challenges its values, it will only be received if the person makes a personal commitment to the challenge. If the challenge feels forced or false, as if being thrust upon them from something outside of that person, and the person is only going along with it, then persuasion is less likely to occur. This is why many departments use officers as instructors of these courses (Kirchbaum et al. 1999, Marion 1998).

Direct data related to denial is evident in passages where the participant tells of biased language and its contexts that fellow officers use. It is also evident in the identification of prejudice toward people in the community they encounter on the job. The exceptions to this were both rare and brief. One participant disclosed that they, too, could have, as he put it, the "Why me?" perspective he associated with people who do not want to accept responsibility.

It comes up and it may or may not have any connection to the reality of the situation. So I don't know how to bridge that. Again, I think it's a tendency and truth be told, I might have it. If I get singled out for something: "Oh, why me?" 
Another said that, although he did not believe he or the other members of his department practiced biased policing methods, he noted that "... at the same time, sometimes we can all say things. You know whether joking or whatever... that are not appropriate."

Finally, the only salient expression of an overarching racial bias in American culture was well said by Participant G. He asserted he wanted the instructors to speak frankly about the existence of bias.

I think especially in a law enforcement aspect, you need to - for a training to be impacted - you need to just come out and say what you're trying to say instead of skirt around the issue. You know, maybe just come out and say, you know, "We know there's racism on all sides... not just, you know: white against black, white against Hispanics", so on and so forth. There's racism everywhere and we have to be aware of it. We have to be able to confront it because that's not only our job, but it's morally right.

Perhaps Participant G would support Armour's (2008) disassociation modeling strategy for counteracting the effects of our racially prejudiced society (Perry 2001, Altman 2000, Walker et al. 2000, Wise 2008, McKinney 2000, Brown, et at. 2003).

\section{AVOIDANCE OF THE TRAINING}

Every participant hypothesized some degree of reluctance or skepticism from their fellow officers before attending this type of training. For example, one participant responded by noting his own reservations about it and was unsure of the training's value prior to attending it. In fact, of all the participants in this study, he noted the greatest level of personal reservation before attendance. This, as it was learned, was not necessarily a mark of prejudice on the part of the participant. To explain, he discloses impressions similar to 
the ones other participants presumed of their peers:

I, as a police officer at least, you know, I think a lot -- I don't think I'm that much different than anybody else, but you're thinking that's not the -- that's not the fun stuff. That's not, you know, doing defensive tactics or shooting your gun or -- So, I mean, I didn't know what kind of value I was going to get out of the training.

Other participant's corroborated this evidence by adding, "There would be the initial skepticism." One expanded on this by stating:

I think we all have that. I mean, no offense to the academy, but it's always been kind of... $d r y$... you know, in the training. And you kinda see the ethics training and you kinda do the, "Ohhbh..." You know? I guess you don't know what to expect sometimes.

Similarly, another participant remarked on their preconception of these trainings:

But it's just -- it's going to be a looong day of, you know, 'We already know we're not supposed to do XYZ.'

Evidently, low priority and reservations regarding racial profiling training appears common among hesitant officers, at least initially. These responses echo the answers of other participants; that the average officer approaches these trainings with a negative perception but not specifically in regards to the content, but rather the format and approach the instructor may take.

More pointed negativism is found in the following quotes from one participant:

...I think that's a natural cynicism on most police officers. I think it'd be really hard to overcome that. 
And later again:

...I think myself and several other people that went to it were kind of viewing this as, "Oh great! Another course on how evil police officers are."

Here the data reveal yet more evidence of a negative preconception of the training, but from a slightly different perspective; officers may feel the training is intended to correct their actions or perception of racial minorities when they believe they do not possess a negative perception or bias (Helfand 2005, McKinney 2000).

Again, every participant to this study reported a skeptical or aversive preconception of what the training would entail. The data reveals that this general uncomfortable approach is a combined effect of past feelings like police officers are made out to be "evil" in these trainings along with reluctance to be subject to lecture style training with minimal interactive content.

Perceptions may have a better chance to shift when people are around to talk with others and influence each other. Social conformity is a powerful force enabling bonds to form between individuals. Once these officers the participants envision as being skeptical change their attitudes about the training and begin to invest themselves in the concepts, tactics and values communicated through the lessons and insight officers who hold negative stereotypes of people-of-color may shift their perspectives to the positive. Time, of course, is required for this to occur, one training session every few years is improbably going to shift attitudes and perceptions unless positive reinforcement regularly occurs as part of their organization's culture (Loftus 2008; Gagliardi 1986).

Adding some insight into why this occurs, one participant revealed an interesting angle on officer reluctance. For him and his fellow officers reluctance could originate from 
recent focus on cultural awareness projects for department accreditation purposes:

"We just went through this." and I was like, "Well this is something different. This is a different format."

In this instance, the participant noted he had to persuade his colleagues to attend after hearing complaints that the training would be "more of the same". It denotes that the typical ethics training modalities are characterized as dry and boring. In this case, the perception that information will be redundant in its presentation is much more concerning, because of the fact that the distant past experiences taint the current approach, as opposed to the inundation of recent attention to racial profiling and multiculturalism.

The telling nature of this revelation may shed light on an outsider's preconceptions about the police force and their reluctance to hold cultural training in the same esteem as their tactical training. Their peers' reluctance to attend these trainings may be born out of their recent history with similar training topics and presentations, as well as the perception that the information can be redundant. Therefore, it is important to understand the reasons why officers feel skeptical, reluctant, or avoidant of these trainings.

\section{DISCUSSION}

The central concern of this research was to examine a current anti-racial profiling seminar's ability to impact the perceptions law officers have of racial minorities. Because, as a few of the participants mentioned, the number of attendees at a few of the trainings appeared lower than expected, it may be an indicator of the level of priority this type of training garners in the minds of individual police officers in Oregon. Since the trainings were said to be sparsely attended, their potential to impact the perspectives of officers who 
"say a lot of racial things" and need to "have an official conversation" about it, may not be exposed to it. It's unfortunate because the training was well regarded and thought of as potentially effective on problem attitudes some officers may have. However, the instructors, although credible and engaging appeared to minimize the importance of the opening framing exercise which may have helped the attendees solidify and focus their attention on the topic. Remember, as George Gascon, 2001 Commander of the LAPD Training Group, said in the opening quote, "Training not only prepares officers for the job, it also serves as a laboratory where we can think deeply about the meaning and essence of policing in a democratic society." (Glenn et al. 2003:63). Because the opening exercise was minimized the officers in attendance may not have been persuaded to dig beneath the surface of the cultural stereotypes about people-of-color that our culture has developed and not yet come to full terms with (McKinney 2000, Helfand 2005, Wise 2008).

\section{Theoretical Implications}

Recall that all participants of this study are white males and all of them disclosed they had been made "reaware" of the difficult police - race intersecting relationship. To underline this point, Participant D disclosed reflecting on his peers' reaction to reading descriptions of previous, and possibly this, racial profiling trainings there is what he called "the 'Ob' Factor". This, in his description, is the response to reading the training title and his assumption that the training was going to be another boring, "loooong" day and, in the words of Participant C, “a waste of time.” Aside from life events that keep people from attending trainings (e.g. personal emergencies, family needs, healthcare appointments and others), the data presents evidence, through these participants' suggestions of improving the 
training description on the DPSST website, that the training is avoided on the part of these unaccounted-for, potential attendees. Some avoidance may be attributed to a conscious or subconscious level of bias.

A White Studies scholar may argue that the collective "'Ob' Factor", that a few participants in this research alluded to, may be indicative of a systemic form of racial or ethnic prejudice. Another way of thinking about this issue is that the officers who could have attended and chose not to, for whatever reason, have put themselves at a disadvantage in terms of how they relate to the racial minority community because they have not been made (re)aware of the repercussions of racial profiling, and how it applies to police - race relations. However, this is not to assert that those officers who did not attend are more racially prejudiced than those who did. Without further research these unaccounted for potential attendees will remain an unknown factor in the study of anti-racial profiling trainings' impacts on officer perceptions of people-of-color.

In short, it appeared a few of the participants believed senior staff neglect and avoid anti-racial profiling trainings based on previous experience and non-engaging training descriptions, appear, based on the reported data, to contribute to low numbers of officers to attend these types of trainings. This directly affects the impact this anti-racial profiling training may have had on members of the police force who did not attend. Some data, evidenced by the following quotes from study participants: "I think this training would help a couple officers that we have. We have one I'm thinking about hitting with a $2 x 4$ because he never seems to think before he speaks. He'll say a lot of racial things,", "for a training to be impacted - you need to just come out and say what you're trying to say instead of skirt around the issue," and "There's racism everywhere and we have to be aware of it," force us 
to conclude that some officers may potentially benefit from and be impacted by this training, but only if they attend it.

Several participants to this study noted an acute observation that the trainings were sparsely attended by their peers. Participant F expressed a level of frustration with poor attendance; in his assessment, "half the people who signed up" did not actually attend.

\section{Police Policy}

The findings of this research, if utilized, could benefit police training policy. On a hypothetical level, participants were asked to assess how they felt their fellow officers would react to the training. Changes in how officers perceive these trainings are small but important starting points on the way to fostering the examination of their perceptions of the racial hierarchy. To underscore this, Participant G commented "there will always be that initial skepticism" marking a barrier to officer participation in this type of training using the previous format of lecture style instruction. He also made clear officers' perceptions of other anti-racial profiling trainings may be tainted by their reflections of the "boring", passive, and non-engaging ethics training block from the academy. In their responses, other participants reflected on the culture of the police and their immediate department; from these responses we gain better understanding of the average officer's perception and how they might be impacted.

This research has revealed that previous racial profiling and ethics trainings were not well received by police officers and they tend to be put on the defensive by the training's instructors or content. Therefore, the overwhelming positive feedback from the participants of this study that a similar training experience may impact or even challenge negative 
stereotypes held by some officers should support a move by the Oregon Department of Public Safety Standards and Training (DPSST) to adapt this regimen to the whole of the Oregon police force in the future. This could be accomplished by integrating it into the current ethics training curriculum at the DPSST academy as well as establish on-going ethics, cultural and racial profiling trainings available to police officers as regional seminars throughout different locations in the state.

\section{$\underline{\text { Social Policy }}$}

The implications of this research to social policy, based on the data collected, are that racism still exists in our culture, ('There's racism everywhere and we have to be aware of it." - Participant G) and the participants reveal a gap in racial awareness among the white, dominant culture. As Walker, et al. (2000), Altman (2000) and Perry (2001) may attest, racism remains an integrated part of American socialization and because police officers are not unlike the majority of Americans in regards to racial prejudice, (Walker, et al. 2000) more white Americans may need to address racial prejudice, perhaps through Armour's (2008) suggestion of dissociation modeling, and dialogue between whites and people-of-color about the meaning of race and the vestiges of America's racial history.

\section{CONCLUSION}

Data collected to answer the three research questions posed in the first chapter, sparked by the fatal outcomes of unarmed people-of-color with police in the Portland, Oregon metro area, were analyzed and the following conclusions can be made. Question 1, 
the central question of study, asks, "Do police officers report their perceptions of people-ofcolor being impacted as a result of participating in an anti-racial profiling training seminar?" Six of the seven participants firmly reported the training had not significantly impacted their perspectives of people-of-color but that it had made them "reaware" of police-race relations. In that regard, the theme of (re)awareness served as an indicator among the participant data that the training had a subtle impact to their sensitivity to race and how they navigate as an active police officer in a diverse community.

With respect to Question 2, "Do police officers from the state of Oregon report having held a stereotyped perception of racial / ethnic community members before attending an anti-racial profiling training?", the data supports a conclusion that the participants involved overwhelming (100 percent) reported to hold no stereotyped perception of people-of-color based on every participant response to interview question 2(c), "Since going through training has it changed the way you interact or perceive members of racial and ethnic communities?", was similar to Participant A's response. He said, "I don't think so," because, "It wasn't a lot out of line from what I was thinking," and, "It would be like me going to a quit smoking course and I don't smoke."

Regarding question 3, "Do police officers from the state of Oregon express having held a perception of members of the racial / ethnic community as individuals prior to attending an anti-racial profiling training?" the data collected overwhelming supported the conclusion that all of the participants (100 percent) reported to perceive members of racial minority groups as individuals. This is based on comments like that of Participant G who stated he judges all people on whether they are "good-hearted" and he developed his nonracially biased outlook through living in a military family and having to live in many different 
locations throughout his life.

The officers who did attend the training and who were part of this study unanimously stated the training exceeded their expectations. They reported the seminar was interactive, multifaceted, and unlike similar prior ethics and anti-racial profiling trainings they had been exposed to in the police academy. The participants noted their positive reactions and assessments of the training format, delivery, and method but a general avoidance of these anti-racial profiling trainings based on perceptions that they are boring and a waste of time persists among their colleagues. This feedback tells us the old "formula" for ethics and anti-racial profiling training is in need of improvements to accomplish the original goals of these racial awareness, anti-racial profiling, cultural sensitivity trainings. The seminar, as reported by the participants in this study, came close to meeting the officer's unstated standards for professional ethics training. This indicates promise for future training programs related to anti-racial profiling and cultural diversity trainings, in general. When officers stop thinking of the training as "a waste of time", or dry in content, and more of them decide to attend then progress toward an increased egalitarian relationship between people-of-color and the police. If the police are less resistant to the way the training is delivered, they might have more positive reflections on the content. This implies adapting this training model to the DPSST academy and as an on-going regional seminar has the potential to become an effective learning strategy toward overcoming other conflicts between law enforcement personnel and people-of-color.

Through the scope of Whiteness Theory, I identified the issue of racial profiling and undertook a critical examination of a cutting edge model for addressing it. The seminar was received well by the participants who speculated their peers would feel the same, as revealed 
in the follow-up interviews. The implications of this research have addressed several tenets of Whiteness Theory which appear to support the continuance of skepticism remains among many police officers about the format of anti-racial profiling trainings which enable them to remain unaware of the important content.

As mundane an improvement as changing the name of the training and creating more descriptive and enticing information about it, it appears critical because, as the data reflects, prejudice exists in some corners of law enforcement in tandem with its existence in other segments of society (Altman 2000, Walker et al. 2000) and officers may not be attending due to negative experiences with past training formats. Learning, or challenging one's perspective, may have a better chance of occurring when people congregate and discuss the issues impeding positive solutions (Armour 2008, Dunham and Wilson 2008). Once "average officers" adopt new attitudes about racial profiling training and greet the training openly, more who hold negative stereotypes of people-of-color, may begin to invest themselves in the concepts, tactics, and values communicated through its lessons and insight. Time, of course, is required for this to occur; one training session every few years is improbably going to have lasting effects on one’s perceptions unless positive reinforcement regularly occurs as part of their organization's culture (Loftus 2008; Gagliardi 1986, Armour 2008).

The addition of Critical Race theoretical tenets to the reviewed anti-racial profiling training may encourage future attending officers to reflect on and critique their perceived position(s) in the American race hierarchy. Critical Race theory could prove valuable to police anti-racial profiling trainings because of its focus on the functions of 'in-group' and 'out-group' bias and identification methods. In short, Critical Race theory asks the observer 
to consider how they identify as a member of racial group and how that is used to differentiate themselves and the group to those thought of as different from the group. It also postulates that these lines of racial demarcation set up value judgments, in effect biases, for the in-group's values to the detriment of the out-group's. Asking questions driving at these divisive methods at the opening of the training may help future officers focus on self identification as "police officers" in comparison to what a "criminal" looks like in racial terms and prejudicial thoughts surrounding this relationship. The data cautions that, however, a confrontational application of this theoretical discussion may disengage the officers. To avoid this, discussions may need to be facilitated using anonymous responses from the group such as by writing them down on cards and the instructor reading them aloud and asking for reflection by the training attendees.

In addition, the research adds to the literature on the impacts and outcomes of antiracial profiling, cultural diversity or ethics trainings among police officers in Oregon by describing some of the reasons why these types of trainings are avoided. The answer is not as simple as Oregon police officers are or are not racially prejudiced and that keeps them from attending elective ethics trainings which in turn, keeps their perceptions of members of racial minority communities static. To the contrary, the research revealed these types of trainings might be avoided because of an experience based preconception that the trainings are a stale, redundant format that ask little interaction on the part of the officer. This barrier may impede some officer perceptions of people-of-color being impacted in some way because in the training experienced, the research participants attested it was well received, supportive of their roles as active police officers within a racially diverse society, and potentially provocative for officers with suspect racial prejudices. 


\section{LIMITATIONS}

Although insightful data were collected regarding how the participants thought this racial profiling training had affected themselves and could affect their peers, limitations to a full understanding of the topic remain. The racial tolerance of the participants involved, the number of participants involved, the void of gender, racial and ethnic diversity within the participant sample, researcher ethnicity, and the method used to gather data all served to limit what data was collected and how it was analyzed.

Being a study which examines bias within the police force, a topic typically very controversial in the profession, it is likely to entice only those with positive views of peopleof-color and those with strong opinions. The sample's demographics and data suggest this was true. A common reflection regarding whether they felt the training had affected the way they interact with people-of-color was well stated by Participant A, who declared the training content "wasn't a lot out of line from what I was thinking". Assuming complete honesty in his response, it implies he already had at least a neutral ideological view of members of racial minority communities and not a negative overall perspective of them. Therefore, officers unlike him, who hold less than positive views about the training and people-of-color, were less likely to volunteer for the research and perhaps the training. The absence of this portion of the population leaves a full understanding of the topic open to debate and critique. However, once tension surrounding the confluence of race and police is alleviated, the risk of distorted representation of data, due to participant anxiety regarding the social undesirability of one's true beliefs, should enable greater understanding of the truth. Because the sample size was minimal and those officers that "can say some pretty racial 
stuff” or "joke and say inappropriate things" were not well represented, at this time, a complete analytical range of responses remains elusive.

Secondly, to address the shortcomings of the data, 2 officers (29 percent) used language suggestive of frustration towards others in their departments. One directed his irritation at a fellow officer who uses racial terms and had to be addressed officially by the supervisor; the other directed his aggravation at his superiors and fellow officers, whom he felt had not supported the training as affirmatively as he would have expected. Although it was important to gather their thoughts on the training's usefulness and improvements, it would be equally beneficial to collect more data from a greater diversity of participants to gain more specific understanding of moderately opinionated officers. This would have enabled a more complete analysis for the purpose of discovering perspectives of racial minorities among "average officers". However, this point assumes a bell-curve relationship on this topic within law enforcement, which may be inaccurate. If the opinion of the population is bi-modal, then extreme opinions may be more accurate. Since sampling of the population was based on availability and the number of participants was low, conclusions cannot be transferred to "the average officer".

Furthermore, study limitations include the small number of participants. Of the 7 different regional trainings, 17 different departments were represented. While it is not known how many total employees could have attended (i.e. the total number of sworn officers available to attend on the given day), nor the total number of officers signed up for the training, (access to DPSST training enrollment was unattainable), it is known that 68 officers had attended the training seminars combined. Of those, 45 returned their completed post-training survey. Inside those surveys, 22 officers expressed interest in a 
follow-up interview and of those, 8 returned a signed consent form and 7 of those were actually reachable. This means 89.7 percent of the officers who attended the trainings, decided not to participate in the study, equating to a massive loss of potential data. Had the study attracted more participants (if $\mathrm{n}$ had equaled 15 to 20 or more), a richer understanding of the topic may have been attained. Data saturation appeared to be achieved in respect to participants' thoughts of (re)awareness, but other focal points, such as racial language among officers, and direct identification of bias within the participant, were not fully developed. In this respect, discovered during the analysis phase of the research process some passages within the data, relating to the above, were not completely explored and remain for future research efforts.

Another point on the limitations of this study is the void of gender and ethnic diversity within the sample. For example, there may be differences between white officers and officers-of-color in their assessments of members of racial minority communities and what they think of racial profiling training. Previous research has examined this race dynamic, but, because no people-of-color or women were attracted to the present project, this factor could not be examined. The insights an officer-of-color could bring to this type of research would be invaluable and must be reserved for future study. Despite this seeming fault, it should be noted the sample consisted of only white males, the target group demographic of these types of trainings. African-American, Latino, Asian-American, Native-American or female officers would seem to be the most likely people eager to engage in discourse regarding the marginalized, and yet this did not occur. Because only white, male officers were participants in the study, future research may capitalize on further investigation as to why officers from other minority groups were less inclined to participate. 
In addition, it should be noted that my ethnicity and my role as interviewer / researcher certainly could have attributed to some bias within the collected data. Being a white, heterosexual male may have elicited certain information from the participants in kind to being identified as part-insider. In kind, experiencing culture from the same point of view, likely prevents certain information from being drawn forth. Furthermore, data may have been analyzed differently had a black lesbian conducted this project or any other combination of social identities besides white, heterosexual male. Moreover, different follow up questions may have been asked eliciting greater critical insight into the issue, had a black female interviewed the officers.

Finally, because telephones were used to gather data, richness was truncated. The use of telephones to interview participants of this study was a necessity but a hindrance because it limited full communication between interviewer and participant. The interviewer was not able to read any participant's body language and, instead, was restricted to interpreting nuances of speech content and voice inflection. The absence of face-to-face interaction may have contributed to some misinterpretation or incompleteness of data. During some interviews, especially the earlier conducted interviews, some key comments were not fully investigated because of restrictions inherent with a telephone interface.

Despite this, the collected data appear to answer the research questions satisfactorily because the standards of case study research design were largely adhered to. In review, they are Construct Validity, Internal Validity, External Validity, and Reliability (Yin 2009). The findings and conclusions came from multiple sources through survey data, interviews, and field notes. The data was organized into a series of steps, survey data and follow-up 
interviews, establishing a chain of evidence (Yin 2009). Although the data did not reveal a significant causal relationship between officer exposure to anti-racial profiling training and a reduction in preconceptions and racial prejudice, during the analysis phase themes emerged that matched patterns established in the theoretical foundation of the research regarding white privilege and denial. The data has limited transferability due to the narrow scope of the questions asked and using conjecture to generalize these findings to a larger group of police officers would be foolhardy. Moreover, I believe a clear description of the protocol undertaken was achieved in Chapter 4, the methodology. Although a database was not formally devised the data was securely stored and organized and can be accessed easily for reference if replication of the research is sought.

\section{SUGGESTIONS FOR FUTURE RESEARCH}

As this research comes to a close, reflection on topics for future research demand attention. Division of the topics is derived from two different origins; methodological enhancement and content accuracy. Advancements of racial profiling training, involving both aspects, would bring about new information and possibly richer understanding.

Methodological advancements include a follow-up study with the next round of officers to undergo the same training seminar in the future, use of in-person interviews rather than telephonic interviews, and participant observation, where the researcher becomes an officer and examines aspects of bias from within the subculture (Marion 1998). Similar studies have already been conducted in other regions and cities in the United States but not in Oregon. Oregon, as explained in Chapter Four, has unique geographical regions that have fostered variation of opinion on social topics and current events. Generally, these divergent 
regions hold fast to their political beliefs and opinions regarding race, culture, and ethnicity. Further research in Oregon could expand and find clarity in the range of opinion within rural-conservative environments and between urban-liberal, rural-liberal, and urbanconservative environments. Further research specific to region may help clarify how similar racial profiling training is received and challenges racial prejudice inside the policing institution of Oregon. 


\section{ENDNOTE:}

${ }^{1}$ Urban has been defined by the U.S. Census Bureau as: All territory, population, and housing units located within urbanized areas and urban clusters. Urbanized Area (UA) is defined as a densely settled area that has a census population of at least 50,000. A UA generally consists of a geographic core of block groups or blocks that have a population density of at least 1,000 people per square mile, and adjacent block groups and blocks with at least 500 people per square mile. A UA consists of all or part of one or more incorporated places and/or census designated places, and may include additional territory outside of any place. See central place, extended place, urban, urban cluster. Urban Cluster (UC) is defined as a densely settled area that has a census population of 2,500 to 49,999. A UC generally consists of a geographic core of block groups or blocks that have a population density of at least 1,000 people per square mile, and adjacent block groups and blocks with at least 500 people per square mile. A UC consists of all or part of one or more incorporated places and/or census designated places; such a place(s) together with adjacent territory; or territory outside of any place. See central place, extended place, urban, urbanized area. However, most participants came to the seminars from rural locales. Rural is simply defined by the U.S. Census Bureau as the opposite of urban or all territory, population, and housing units located outside of urbanized areas and urban clusters. 
$\underline{\text { Table } 1}$

Comparison of State and County Ethnic Demographics as Percentage of Estimated Total Population

\begin{tabular}{lrrr}
\hline & \multicolumn{2}{c}{ Year 2007 Estimates } \\
\cline { 2 - 3 } & \multicolumn{2}{c}{ State } \\
\hline \multirow{2}{*}{ Total Population } & 20,687 to 343,591 & $3,747,455$ \\
White & & \\
Black & 91.5 & 90.3 \\
Native & 0.8 & 2.0 \\
Asian & 4.1 & 1.4 \\
Pac. Islander & 1.2 & 3.7 \\
Hisp. / Latino & 0.2 & 0.3 \\
White not Hisp. & 9.9 & 10.6 \\
Multiethnic & 82.4 & 80.5 \\
& 2.3 & 2.4 \\
& & \\
\hline
\end{tabular}

*Mean percentages of County data.

$*_{\mathrm{n}}=7$ 
Figure 1

\section{Frequency of Responses to Item 5 of Initial Assessment Survey}

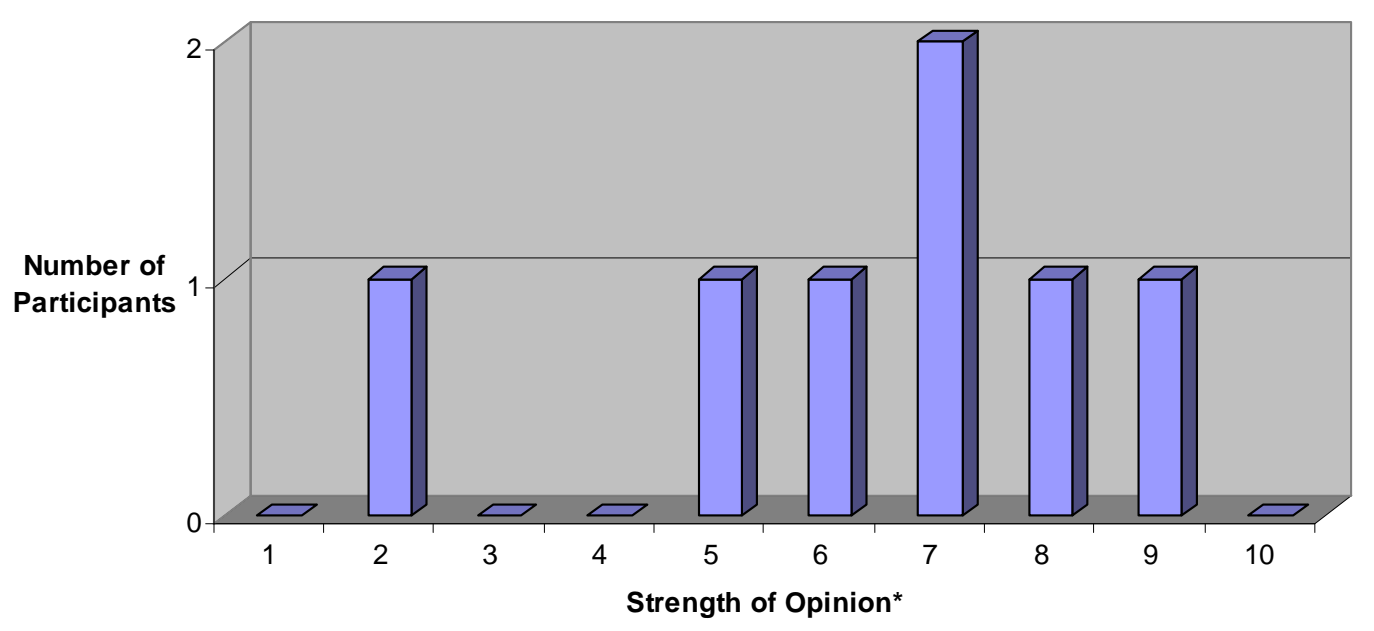

*10 point scale assessment $(1=$ strongly disagree, $10=$ strongly agree $)$

Item 5 - "The trainers and content matter challenged my opinions about race and police."

Mean $=6.286$

$\mathrm{s}=2.289$

$\mathrm{n}=7$ 
Figure 2

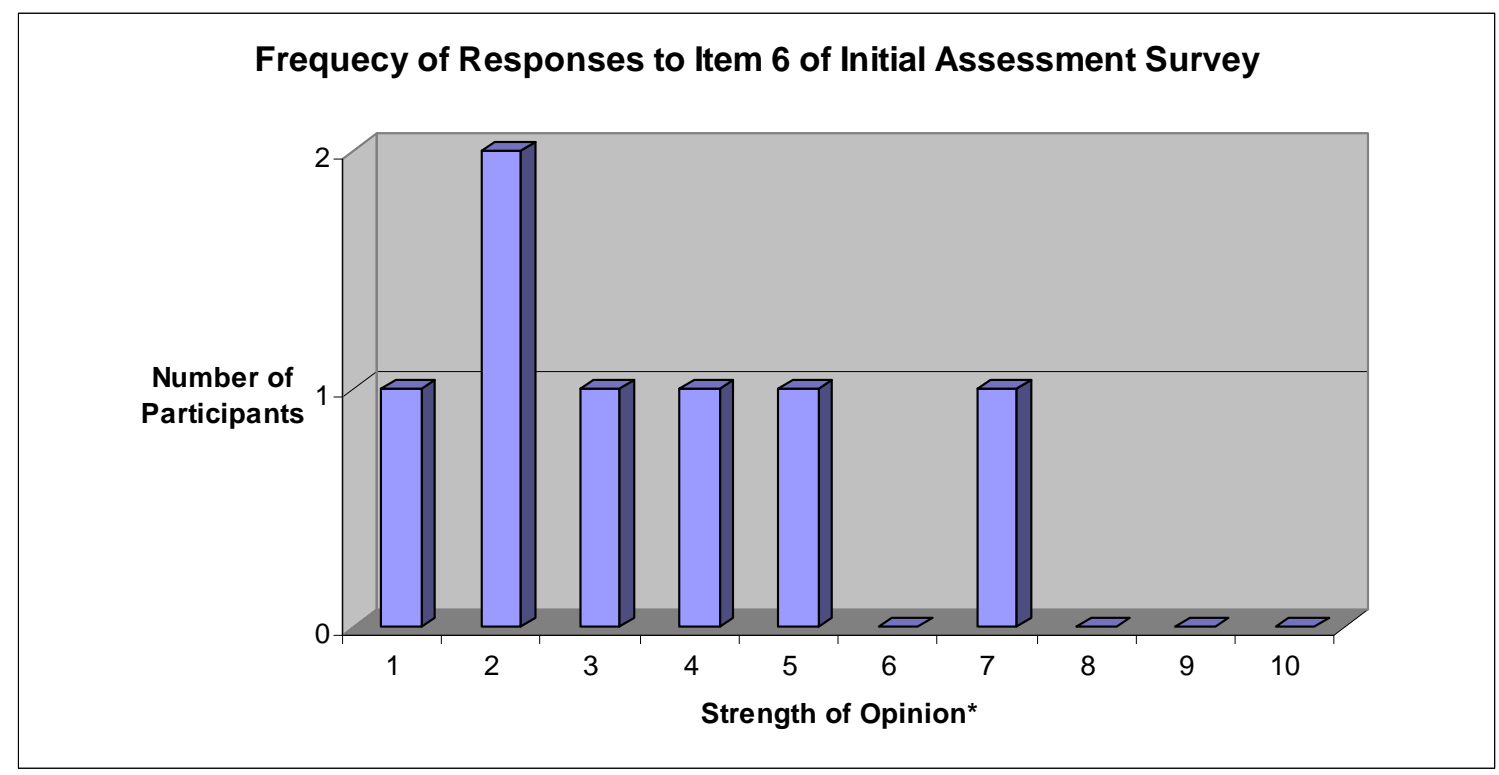

$* 10$ point scale assessment $(1=$ strongly disagree, $10=$ strongly agree $)$

Item 6 - "The training seemed "watered-down", meaning it didn't confront the difficult issues of race, police and bias."

Mean $=3.429$

$\mathrm{s}=2.070$

$\mathrm{n}=7$ 


\section{REFERENCES}

Akinyela, Makungu M. and Dolores P. Aldridge. 2003. "Beyond Ethnocentrism, Afrocentrism and Multiculturalism: Toward Cultural Democracy in Social Work Education.” Race, Gender \& Class 10(2):58-70.

Altman, Neil. 2000. "Black and White Thinking: A Psychoanalyst Reconsiders Race." Psychoanalytic Dialogues 10(4):589-605.

Armour, Jody. 2008. "Stereotypes and Prejudice: Helping Legal Decisionmakers Break the Prejudice Habit.” In Critical Race Realism: Intersections of Psychology Race and Law. Eds. Parks, Gregory S., Shayne Jones and W. Jonathan Cardi, New York: The New Press, $11-32$.

Asher, Nina. 2005. "At the Interstices: Engaging Postcolonial and Feminist Perspectives for a Multicultural Education Pedagogy in the South." Teachers College Record 107(5):10791106.

Avery, John K. 1989. "Professional Responsibility in Australian Policing." Police Studies, 12(4):160-164.

Bargh, J.A., and P. Pietromonaco. 1982. "Automatic Information Processing and Social Perception: The Influence of Trait Information Presented Outside of Conscious Awareness on Impression Formation." Journal of Personality and Social Psychology 43:437-449.

Barlow, David E. and Melissa Barlow. 1993. "Cultural Diversity Training in Criminal Justice: A Progressive or Conservative Reform?” Social Justice 20(3-4):69-84.

Bernstein, Maxine. 2004. "It was Over in Seconds." The Oregonian. Retrieved October 24, 2010 (http:/ /blog.oregonlive.com/washingtoncounty/2008/01/sery.html\#6).

Bernstein, Maxine. 2004. "Shooting Increases Calls to Improve Police Training." The Oregonian. Retrieved October 24, 2010 (http://blog.oregonlive.com/ washingtoncounty/2008/01/sery.html\#6).

Bernstein, Maxine. 2004. “Officers Will Face a Public Inquest.” The Oregonian. Retrieved October 24, 2010 (http://blog.oregonlive.com/washingtoncounty /2008/01/sery.html\#6).

Bernstein, Maxine. 2004. "Police Expand Questioning in Shooting." The Oregonian. Retrieved October 24, 2010 (http://blog.oregonlive.com/washingtoncounty /2008/01/sery.html\#6). 
Bernstein, Maxine. 2009. "Portland Police Rally to Support Officer in Beanbag Shotgun Case.” The Oregonian. Retrieved May 19, 2010 (http://www.oregonlive.com /portland/index.ssf/2009/11/portland_police_support_suspen.html).

Blume, Harvey. 2002. "The Other NYPD Murder." The American Prospect. Retrieved May 19, 2010 (http://www.prospect.org/cs/articles?article=the_other_nypd_murder).

Brown, Michael K., Martin Carnoy, Elliot Currie, Troy Duster, David B, Oppenheimer, Marjorie M. Schultz, and David Wellman. 2003. White Washing Race: The Myth of a Color-Blind Society. London, UK: University of California Press.

Carmichael, Jason T. 2006. The Political Sociology of Juvenile Punishment: Treating Juvenile Offenders as Adults. Dissertation. Columbus, $\mathrm{OH}$ : The Ohio State University Press.

Cashmore, Ellis. 2002. "Behind the Window Dressing: Ethnic Minority Police Perspectives on Cultural Diversity." Journal of Ethnic and Migration Studies (28):327-341.

Chapin, Mark, Stephen J. Brannen, Mark I. Singer and Michael Walker. 2008. "Training Police Leadership to Recognize and Address Operational Stress.” Police Quarterly $11: 338$.

Conley, Darlene J. 1994. "Adding Color to a Black and White Picture: Using Qualitative Data to Explain Racial Disproportionality in the Juvenile Justice System” Journal of Research in Crime and Delinquency, 31(2):135-148.

Cornett-Devito, Myrna M. and Edward L. McGlone. 2000. "Multicultural Communication Training for Law Enforcement Officers: A Case Study." Criminal Justice Policy Review 11(3):234-253.

Das, Dilip, K. 1993. “Canadian Police Perception of Minority Problems.” Police Studies 16(4):138-146.

Dennison, Bryan. 2004. "Rally Calls Police to Account." The Oregonian. Retrieved October 24, 2010 (http://blog.oregonlive.com/washingtoncounty/2008/ 01/sery.html\#6).

Duin, Steve. 2010. "Portland Police Training Leaves Many of us Fuming After Shooting Death." The Oregonian Portland, OR Retrieved October 24, 2010 (http://www.oregonlive.com/news/oregonian/steve_duin/index.ssf/2010/02/ portland_police_training_leave.html).

Dunham, Roger G. and George Wilson, 2008. "Prejudice and Police Profiling." In Critical Race Realism: Intersections of Psychology, Race and Law. Eds. Parks, Gregory S., Shayne Jones and W. Jonathan Cardi, New York: The New Press: 246-258.

Federal Bureau of Investigation. 2010. "Uniform Crime Reports: Crime in the United States, 2010.” Washington DC: Federal Bureau of Investigation. Retrieved October 24, 
2010 (http://www.fbi.gov/about-us/cjis/ucr/crime-in-the-u.s/2010 / crime-in-theu.s.-2010).

Felkenes, George T. 1984. "Attitudes of Police Officers Toward Their Professional Ethics." Journal of Criminal Justice 12(3):211-220.

Friedman, Michael Jay. 2009, “Free At Last:_The U.S. Civil Rights Movement.” The Bureau of International Information Programs, Washington DC. Retrieved October 24, 2010 (http://www.america.gov/st/peopleplace-english/2008 /December/20090106140544jmnamdeirf0.1943018.html).

Gagliardi, Pasquale. 1986. "The Creation and Change of Organizational Cultures: A Conceptual Framework.” Organization Studies 7:117-134.

Garland, Jon and Neil Chakraborti. 2007. "Protean Times?': Exploring the Relationships Between Policing, Community and 'Race' in Rural England." Criminology and Criminal Justice 7:347-365.

George, Alexander L. and Andrew Bennett. 2005. Case Studies and Theory Development in the Social Sciences Cambridge, MA: The MIT Press.

Glenn, Russell W., Barbara R. Panitch, Dionne Barnes-Proby, Elizabeth Williams, John Christian, Matthew W. Lewis, Scott Gerwehr and David W. Brannan. 2003. Training the $21^{\text {st }}$ Century Police Officer: Redefining Police Professionalism for the LAPD Los Angeles, CA: RAND.

Guitart Moises, Esteban and Jose Bastiani Gomez. 2010. "Can an Intercultural Education Model Combat Discrimination and Xenophobia?" Athenea Digital: Revista de Pensamiento e Investigacion Social, 17:(3-16) ::Abstract::

Hannah-Jones, Nikole. 2010. "Black Experience Propels Anger in Police Shooing of Aaron Campbell." The Oregonian Portland, OR Retrieved October 24, 2010 (http://www.oregonlive.com/portland/index.ssf/2010/02/black_experience_ propels_anger.html).

Hawkins, Darnell F., John H. Laub, Janet L. Lauritsen, and Lynn Cothern. 2000. "Race, Ethnicity, and Serious and Violent Juvenile Offending." Juvenile Justice Bulletin U.S. Department of Justice: Washington DC. Retrieved October 24, 2010 (http://people.wku.edu/john.faine/soc332/racedel.pdf).

Helfand, Judy. 2005. "Constructing Whiteness.” Retrieved June 12, 2006 (http://academic.udayton.edu/race/01 race/white11.htm).

Hirsh, Elizabeth; Lyons, Christopher J. 2010. "Perceiving Discrimination on the Job: Legal Consciousness, Workplace Context, and the Construction of Race Discrimination." Law \& Society Review 44(2):269-298. 
Holmes, Malcolm D. and Brad W. Smith. 2008. Race and Police Brutality: Roots of an Urban Dilemma Albany NY: State University of New York Press.

Hyde, Cheryl. 1995. “The Meanings of Whiteness.” Qualitative Sociology 18:87-95.

Kavanagh, John. 1997. "The Occurrence of Resisting Arrest in Arrest Encounters: A Study of Police-Citizen Violence.” Criminal Justice Review, 22(1):16-33.

Krichbaum, Daniel, Linda West and Daedra McGhee. 2001. "Detroit Targets the Elimination of Racial Profiling." Diversity Factor 9(4):18-24.

Kop, Nicolien, Martin Euwerna, and Wilmar Schaufeli. 1999. "Burnout, Job Stress and Violent Behavior Among Dutch Police Officers.” Work \& Stress 13(4):326-340.

Kroes, W. H., B.L. Margolis, and J.J. Hurrell. 1974. "Job Stress in Policemen.” Journal of Police Science and Administration 2(2):145-155.

Kroes, W. H. 1985. Society's Victims : The Police; An Analysis of Job Stress in Policing. Springfield, IL: Thomas Press.

Kurin, Dima. 2008. "Money Whitens but Doesn't Erase: A Reflective Sociology of Racism from the Middle of the American 'Melting Pot' Human Architecture." Journal of the Sociology of Self-Knowledge, 6(2):127.

Lehrer, Paul M., Robert L. Woolfolk and Wesley E. Sime: Eds. 2007. Principles and Practice of Stress Management. New York: The Guilford Press.

Leip, David. 2004. “Atlas of U.S. Presidential Elections.” Retrieved November 15, 2008 (http://uselectionatlas.org/RESULTS/).

Liederbach, John, Chad R. Trulson, Eric J. Fritsch, Tory J. Caeti, and Robert W. Taylor. 2007. "Racial Profiling and the Political Demand for Data: A Pilot Study Designed to Improve Methodologies in Texas." Criminal Justice Review 32(2):101-120.

Loewen, James W. 2008. "Lies My Teacher Told Me: Everything Your American History Textbook Got Wrong.” New York: The New Press.

Loftus, Bethan. 2008. "Dominant Culture Interrupted: Recognition, Resentment and the Politics of Change in an English Police Force." British Journal of Criminology 48(6):756777. ::Abstract::

Marion, Nancy. 1998. "Police Academy Training: Are We Teaching Recruits What They Need to Know?” Policing 21(1):54-79.

McKinney, Kathryn. 2000. “Everyday Whiteness: Discourse Study and Identity.” Presented 
at the annual meeting of the American Sociological Association (ASA), Conference Paper.

Menendez Alarcon, Antonio V and Katherine B. Novak. 2010. "Latin American Immigrants in Indianapolis: Perceptions of Prejudice and Discrimination."

Latino Studies 8(1):93-120.

Miller, Kirk. 2007. "Racial Profiling and Postmodern Society: Police Responsiveness, Image Maintenance, and the Left Flank of Police Legitimacy." Journal of Contemporary Criminal Justice 23(3):248-262.

Novak, Kenneth J. 2004. “Disparity and Racial Profiling in Traffic Enforcement.” Police Quarterly 7(1):65-96.

Oliver, J.E. and Tali Mendelberg. 2000. "Reconsidering the Environmental Determinants of White Racial Attitudes." American Journal of Political Science, 44(3):574-589.

Olzak, Susan, Suzanne Shanahan, and Elizabeth H. McEneaney. 1996. "Poverty, Segregation and Race Riots: 1960 to 1993." American Sociological Review 61(4):590-613.

Scott, John and Gordon Marshall. 2005.Oxford Dictionary of Sociology Oxford, NY: Oxford University Press.

Perlmutter, Philip. 2008. "The Changing Complexity of Prejudice and Discrimination." Society 45:4, 348-353.

Perry, Barbara. 2001. In the Name of Hate: Understanding Hate Crime New York: Routledge Press.

Pitkanen, Pirkko and Satu Kouki. 2002. "Meeting Foreign Cultures: A Study of the Attitudes of Finnish Authorities Towards Immigrants and Immigration." Journal of Ethnic and Migration Studies 28(1):103-118.

Porter, Bruce and Marvin Dunn. 1984. The Miami Riot of 1980 Lexington, MA: D.C. Heath and Company.

Prenzler, Tim and Carol Ronken. 2003. "A Survey of Innovations in the Development and Maintenance of Ethical Standards by Australian Police Departments.” Police Practice and Research 4(2):149-161.

Roediger, David R. 1999. The Wages of Whiteness: Race and the Making of the American Working Class London, UK: Verso Press.

Rowe, Michael and Jon Garland. 2003. “'Have You Been Diversified Yet?’: Developments in Police Community and Race Relations Training in England and Wales." Policing and Society 13(4):399-411. 
Sampson, Robert J. and William Julius Wilson. 2005. "Toward a Theory of Race, Crime, and Urban Inequality." In Race, Crime and Justice: A Reader Eds. Shaun L. Gabbidon and Helen Taylor Greene. London, UK: Psychology Press 177-190 Retrieved October 24, 2010 (http:/ / books.google.com/books?hl=en\&lr=\&id=PsdUi2n8IvMC\&oi= fnd\&pg $=$ PA177\&dq $=$ Sampson + and + Wilson $+2005+$ offending + rates\&ots $=J Y Y M s$ BWMf9\&sig=BaQA1_1_7x7TYBPmeyNpQQElmaM\#v=onepage\&q\&f=false).

Schafer, Joseph A., David L. Carter, Andra J. Katz-Bannister, and William S. Wells. 2006. "Decision Making in Traffic Stop Encounters: A Multivariate Analysis of Police Behavior.” Police Quarterly 9(2):184-209.

Scott, Yolanda M. 2004. "Stress among Rural and Small-Town Patrol Officers: A Survey of Pennsylvania Municipal Agencies.” Police Quarterly 7:237.

The Simon Weisenthal Center Museum of Tolerance 2002. "Perspectives on Profiling: Effective Policing Tool or Weapon of Bias?" Tools for Tolerance for Law Enforcement, CD-Rom.

Sun, Ivan Y. and Doris C. Chu. 2008. "A Cross-National Analysis of Female Police Officers' Attitudes in the United States and Taiwan." International Criminal Justice Review 18(1):523.

Terkessidis, Mark. 2000. “Global Culture in Germany or: How Repressed Women and Criminals Rescue Hybridity” Communal/ Plural 8(2):219-235.

Terry, Lynn. 2010. "Group Calls for Portland Police Officer Ron Frashour to be Fired in Aaron Campbell Killing." The Oregonian Portland, OR Retrieved October 24, 2010 (http://www.oregonlive.com/portland/index.ssf/2010/09/group_calls_for _portland_polic.html).

Tonry, M. 1995. Malign Neglect: Race Crime and Punishment in America New York; Oxford University Press.

Truman, J. L. and M.R. Rand. 2010. Criminal Victimization 2009 Washington DC: U.S. Department of Justice.

Veterans of the Civil Rights Movement, 2005. "We'll Never Turn Back: History and Timeline of the Southern Freedom Movement.” Retrieved November 20, 2010 (http://www.crmvet.org/tim/timhis57.htm\#1957lrsd).

Veterans of the Civil Rights Movement, 2005. "Selma and the March to Montgomery: A Discussion November-June, 2004 - 2005.” Retrieved November 20, 2010 (http://www.crmvet.org/disc/selma.htm\#ala65bloody)

Walker, Samuel, Cassia Spohn, and Mirriam DeLone. 2000. The Color of Justice: Race Ethnicity 
and Crime in America (Second Edition) South Melbourne, Australia: Wadsworth.

Walker, Samuel. 2005. The New World of Police Accountability Thousand Oaks, CA: Sage.

Weitzer, Ronald and Steven A. Tuch. 2005. "Racially Biased Policing: Determinants of Citizen Perceptions." Social Forces 83(3):1009-1030.

West, Candice and Sarah Fenstermaker. 2002. Doing Gender, Doing Difference: Inequality, Power, and Institutional Change.New York: Routledge.

Westman, J. C. and J. R. Walters,.1981. "Noise and Stress: A Comprehensive Approach." Environmental Health Perspectives, 41: October

White, David. 2006. "A Conceptual Analysis of the Hidden Curriculum of Police Training in England and Wales." Policing and Society 16(4):386-404.

Wise, Tim. 2008. White Like Me: Reflections on Race from a Privileged Son. Berkley, CA: Soft Skull Press.

Withrow, Brian L. 2007. 'When Whren Won't Work: The Effects of a Diminished Capacity to Initiate a Pretextual Stop on Police Officer Behavior.” Police Quarterly, 10(4):351370.

Yin, Robert K. 2004. The Case Study Anthology Thousand Oaks, CA: Sage Publications.

Yin, Robert K. 2009.Case Study Research: Design and Methods 4th Ed. Thousand Oaks, CA: Sage Publications.

Young, Malcolm. 1993. In the Sticks: Cultural Identity in a Rural Police Force Oxford, NY:

Clarendon Press.

Zhao, Jihong, Ni He, and Nicholas Lovrich. 2002. "Predicting Five Dimensions of Police Officer Stress: Looking More Deeply Into Organizational Settings for Sources of Police Stress.” Police Quarterly 5(43). 


\section{Appendix A:}

\section{Initial Assessment Survey}

\section{WE'D APPRECIATE YOUR FEEDBACK}

The Law Enforcement Contacts Policy and Data Review Committee (LECC), a partner in this training effort, would like your input and feedback on this training.

Your opinions are important to us.

We'd like to ask you a few questions before and after the training. The questions focus on why you're here today and what you felt about the training.

What will I get out of taking this survey?

Your feedback is important to improving the delivery and effectiveness of this training effort.

If you're willing to participate in a short follow-up phone or email interview we'll enter your name in a raffle for an IPOD music player.

Your answers are confidential

Only our partner, Portland State University (Brian Renauer - 503-725-8090) and his graduate assistant David Kline will have access to your answers, which will be kept strictly confidential. You don't have to answer any questions you don't want to.

THANKS FOR ANY HELP YOU CAN PROVIDE 
Question 1: Please tell us the principal reason or reasons you participated in today's training?

Question 2: As you prepared to attend this training today, what did you think the training would be like or about?

Question 3: What did you like about the training?

Question 4: What did you dislike about the training?

Question 5: How do you feel about the importance of this training for law enforcement officers? 
How strongly do you agree or disagree with the following statements?

Please circle a number from 1 to 10 where $1=$ strongly disagree and $10=$ strongly agree.

1) The trainers engaged us in the subject matter.

Strongly disagree

12

3

4

$5 \quad 6$

$6 \quad 7$

Strongly agree

$9 \quad 10$

2) The trainers were persons we could relate to.

Strongly disagree

12

2

456

7

8

Strongly agree

$9 \quad 10$

3) The trainers had extensive experience in the subject matter.

Strongly disagree

12

2

3

4

$5 \quad 6$

7

Strongly agree

$9 \quad 10$

4) The trainers were able to answer participant's questions.

Strongly disagree

12

2

3

4

$5 \quad 6$

6

$7 \quad 8$

Strongly agree

5) The trainers and content matter challenged my opinions about race and police.

Strongly disagree

12

2

3

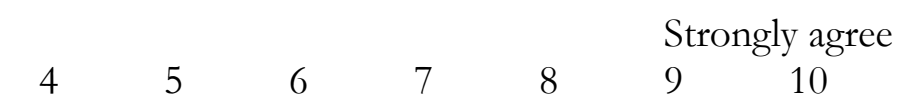

6) The training seemed "watered down", meaning it didn't confront the difficult issues of race, police and bias.

Strongly disagree

12

2

3

4

$5 \quad 6$

$6 \quad 7$

8

Strongly agree

Strongly ag
$9 \quad 10$

7) I would recommend this training to other law enforcement officers.

Strongly disagree

$\begin{array}{llllllllll} & 1 & 2 & 3 & 4 & 5 & 6 & 7 & 8 & 9\end{array}$




\section{ANY OTHER COMMENTS ON THE TRAINING?}

Age?

Gender? Male Female

Current Rank?

Would you be willing to participate in a follow up interview via phone or email?

If yes, we'll enter your name into a drawing for an IPOD music player.

If yes,

Name:

Address, Phone, Email or other means to schedule a time and date for the interview:

Thank you for participating! 


\section{Appendix B:}

\section{Follow-up Interview Schedule}

I'd like to start by asking you a few questions regarding your reflections associated with the Tactical Ethics: Perspectives on Profiling Training you attended in April.

1) Now that you have been through it what do you feel the objective of the training was?

2) What are your thoughts about this training's usefulness to the performance of your job? (Probe if struggling: May have to rephrase meaning of question - Has it been useful to you? How so, Why not?)

Follow-up questions (try not to be redundant if they touched on these above) :

A) Since going through the training have you thought about your department's organizational culture or ethical issues in law enforcement? If yes - How so? If no Why not?

B) Since going through the training have you thought about "the 2-prong test" while on the job? If yes - How so, If no - Why not?

C) Since going through the training has it changed the way you interact with or perceive members of racial and ethnic communities - If yes - How so?, If no Why not?

3) On your survey you put down that you (agreed, disagreed, were middle of the road) that this training seemed "watered down" in that it didn't confront personal biases toward racial and ethnic minority groups - Do you still agree with your assessment? Why was it watered down or not watered down? If necessary - why did you change your opinion?

4) How do you think your fellow officers would feel about attending this training? Why? (Follow up: What do you think could be done to overcome any reluctance to attend?)

5) How do you think your fellow officers would respond to this training after attending it? Was your personal response different? (Follow up: How so?)

6) Do you think this training can help officers be more willing to confront ethical issues in their department? Why or Why not?

Now I'd like to finish with your overall thoughts in evaluation of the training method.

7) Can this training be improved in some way? What are your ideas? (Probe: Is there an aspect of the training that you would like covered in more detail? Less detail? Why?)

8) How would you evaluate the instructors of the training? (Probes: What did they do that "worked"? What could they work on?)

Thank you for participating in this study. The interview is now over. Is there an aspect of cultural relations between police and minorities that this study hasn't addressed or are there any comments you'd like to add? 


\section{Appendix C:}

“'It was over in seconds':

Police Radioed that an Officer Shot James Jahar Perez 24 Seconds after Reporting the Traffic Stop, the Police Chief Says.”

Maxine Bernstein: The Oregonian, Friday, April 2, 2004 -

Twenty-four seconds elapsed between the time that a Portland officer radioed the traffic stop of James Jahar Perez on Sunday to an officer's radio call that shots were fired, Portland Police Chief Derrick Foxworth disclosed Thursday.

The first radio call may have come as the officer already had stepped from his car and was approaching Perez in the parking lot of the Lucky Day Cleaners \& Laundry, Foxworth said.

Officer Jason Sery, 29, and his partner, Officer Sean Macomber, 30, pulled over Perez at 5:07 p.m. Sunday at North Fessenden Street and North Burr Avenue for failure to signal within 100 feet of making a turn. In less than 30 seconds, Sery had fired three shots from his $9 \mathrm{~mm}$ at Perez because Sery thought the motorist was armed, police said.

Perez, 28, died from a wound to the chest.

Macomber, who had been struggling to remove Perez from the front seat of the car after he failed to produce a driver's license or identification, then fired his Taser gun at the driver.

The chief said he didn't recall a similar occurrence in Portland in which an officer had fired a Taser after a firearm was used.

The cycle of the Taser lasted 3 minutes, 19 seconds, Foxworth said. Detectives determined the length of the Taser cycle by examining the data cartridge attached to the weapon. One of the electric probes struck Perez in the forearm; the other hit a car seat, police said.

"I don't think we've had other situations where the Taser has been cycled that long," Foxworth said.

However, a spokesman for the stun gun's manufacturer said late Thursday that the length of the cycle wouldn't have mattered, since only one of the darts hit Perez's body and he likely didn't receive a shock. "Think about electricity," said Mark Johnson of Taser International. "You have to have a positive or a negative to get it to work. If one (probe) hit the seat, there is no way he received a shock."

Even if both darts had hit their target, the gun would need to discharge 400 times more electricity to be lethal, he said. Also, he said the length of the cycle was the longest he had heard 
during its use by police forces around the country.

City settles separate Sery case

In another case, the city of Portland paid a $\$ 5,000$ settlement in January to a Portland man who claimed Sery and another police officer used excessive force against him in 2001.

Martin Dennis claimed that he was at the Astro gas station at 2809 N. Portland Blvd. on Aug. 26, 2001, when he was knocked unconscious by police. He claimed that he suffered injuries to his head, right ear and right eye.

In the August 2003 federal lawsuit, Dennis named Sery as a defendant and asked for a combined $\$ 355,000$ in damages from the city.

The city said in court records that Dennis was injured while being taken into custody but that Sery arrived at the scene after Dennis already had been handcuffed and placed in a police car.

As part of the settlement, the city did not admit any wrongdoing on the part of the officers. Dennis declined to discuss the case Thursday.

Foxworth said Thursday that he expects to set up a joint police-citizen use of force review board by July 1 that would examine all deaths in police custody, use of less-lethal weapons and deadly force.

Under preliminary plans, the board would consist of three assistant chiefs, a police commander who is not the supervisor of the officer in question, an officer's peer representative such as a fellow officer or sergeant and two to three citizens. How the citizens would be selected has not been determined. 